\title{
Global Disorders of Sex Development Update since 2006: Perceptions, Approach and Care
}

\author{
Peter A. Lee ${ }^{a} \quad$ Anna Nordenström ${ }^{b} \quad$ Christopher P. Houk ${ }^{c}$ S. Faisal Ahmed ${ }^{d}$ \\ Richard Auchus ${ }^{e} \quad$ Arlene Baratz $^{f}$ Katharine Baratz Dalke ${ }^{g}$ Lih-Mei Liao $^{\text {h }}$ Karen Lin-Su $^{\mathrm{i}}$ \\ Leendert H.J. Looijenga 3rd ${ }^{j}$ Tom Mazurk Heino F.L. Meyer-Bahlburgl ${ }^{\text {Pierre Mouriquand }}{ }^{m}$ \\ Charmian A. Quigley $^{f, n}$ David E. Sandberg ${ }^{\circ}$ Eric Vilain ${ }^{p} \quad$ Selma Witchel $^{q}$ \\ and the Global DSD Update Consortium

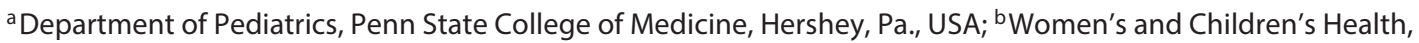
Karolinska Institutet, Karolinska University Hospital, Stockholm, Sweden; ${ }^{\circ}$ Department of Pediatrics, Georgia

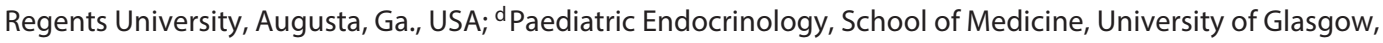
Glasgow, UK; ${ }^{e}$ Metabolism, Endocrinology and Diabetes, DSD Program, University of Michigan Health System, Ann Arbor, Mich., ${ }^{\mathrm{f}}$ Androgen Insensitivity Syndrome - Differences of Sex Development Support Group, Duncan, Okla., and ${ }^{9}$ Department of Psychiatry, University of Pennsylvania School of Medicine, Philadelphia Pa., USA; hWomen's Health Division, University College London Hospitals, London, UK; i Pediatric Endocrinology, Weill Cornell Medical Center, New York, N.Y., USA; 'ंDepartment of Pathology, Erasmus MC University Medical Center, Rotterdam, The Netherlands; ${ }^{k}$ Department of Psychiatry and Pediatrics, School of Medicine and Biomedical Sciences, SUNY at Buffalo, Buffalo, N.Y., and 'New York State Psychiatric Institute and Department of Psychiatry, College of Physicians and Surgeons, Columbia University, New York, N.Y., USA; m Pediatric Urology, Hospices Civils de Lyon, Claude-Bernard University, Lyon, France; ${ }^{\mathrm{n}}$ Indiana University School of Medicine, Indianapolis, Ind., o Pediatric Psychology, Pediatrics, and Child Health Evaluation and Research (CHEAR) Unit, University of Michigan,

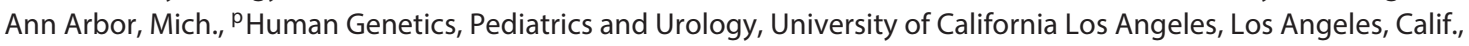
and 'Endocrinology and Diabetes, Children's Hospital of Pittsburgh, University of Pittsburgh School of Medicine, Pittsburgh, Pa., USA
\end{abstract}

\section{Key Words}

Disorders of sex development $\cdot$ Intersex $\cdot$ Ambiguous genitalia

\section{Abstract \\ The goal of this update regarding the diagnosis and care of persons with disorders of sex development (DSDs) is to address changes in the clinical approach since the 2005 Consensus Conference, since knowledge and viewpoints change. An effort was made to include representatives from}

a broad perspective including support and advocacy groups. The goal of patient care is focused upon the best possible quality of life (QoL). The field of DSD is continuously developing. An update on the clinical evaluation of infants and older individuals with ambiguous genitalia including perceptions regarding male or female assignment is discussed. Topics include biochemical and genetic assessment, the risk of germ

Karen Lin-Su is the Medical Director of CARES (Congenital Adrenal Hyperplasia Research Education and Support) Foundation.

\section{KARGER}

E-Mail karger@karger.com www.karger.com/hrp
(C) 2016 S. Karger AG, Basel

$1663-2818 / 16 / 0853-0158 \$ 39.50 / 0$
Peter A. Lee

Department of Pediatrics, Penn State College of Medicine

Milton S. Hershey Medical Center, Box 850

500 University Drive, Hershey, PA 17033-085 (USA)

E-Mail plee@psu.edu 
cell tumor development, approaches to psychosocial and psychosexual well-being and an update on support groups. Open and on-going communication with patients and parents must involve full disclosure, with the recognition that, while DSD conditions are life-long, enhancement of the best possible outcome improves QoL. The evolution of diagnosis and care continues, while it is still impossible to predict gender development in an individual case with certainty. Such decisions and decisions regarding surgery during infancy that alters external genital anatomy or removes germ cells continue to carry risk.

(c) 2016 S. Karger AG, Basel

Disorders of sex development (DSDs) were defined as congenital conditions within which the development of chromosomal, gonadal and anatomic sex is atypical at the Chicago Consensus Meeting in 2005 [1]. This is an update since the Consensus Statement published in 2006. Perceptions and the approach to the diagnosis and care of individuals with DSDs continuously change. Data remain inadequate to address major concerns including the assignment of male or female sex, predictors of gender identity development, surgical issues regarding timing and consent and the best possible fertility preservation measures. It is clear than gains in perceptions, approach and care since 2006 need to be reviewed and considered. A large number of individuals with differing opinions participated in the endeavor. The following update has been endorsed by the European Society for Pediatric Endocrinology (ESPE), the Pediatric Endocrine Society (PES-NA), the Australian Pediatric Endocrine Group (APEG), the Asian Pacific Pediatric Endocrine Society (APPES), the Japanese Society of Pediatric Endocrinology (JSPE), the Sociedad LatinoAmericana de Endocrinologia Pediatrica (SLEP) and the Chinese Society of Pediatric Endocrinology and Metabolism (CSPEM).

\section{DSD Nomenclature}

The broad term DSD, adopted at the Consensus Conference, has been generally accepted by many medical professionals but not universally by some patient and support groups $[1,2]$. Positive aspects about having a term include providing for scientific accuracy within a biological and medical context, bona fide genetic disorders facilitate access to healthcare and insurance, an umbrella classification helps in generating comprehensive

Global Disorders of Sex Development

Update since 2006 and integrated models of care, at the same time it avoids confusion by not overlapping with conditions such as transgender, gender dysphoria and homosexuality, and it provides a framework for knowledge accumulation and research funding.

Negative connotations of DSD perceived by some advocacy organizations [3] include the stigma of 'disorder' and perceived implications that 'sex' involves sexual behavior. The term DSD is not felt to be applicable to all individuals included, such as males with congenital adrenal hyperplasia $(\mathrm{CAH})$, resulting in participant refusal regarding research under this heading [2]. Some people consider 'intersex' to be a better term than DSD, especially for infants requiring male or female assignment, some substitute the word 'disorders' by 'differences', whilst still others call for an alternative nomenclature.

\section{Incidence}

The terminology has led to confusion regarding the incidence of conditions included [4]. There are no clear estimates of the incidence rate of subjects presenting with ambiguous genitalia at birth, and only a proportion of them present a major challenge regarding male or female assignment. However, it has been estimated to be approximately 1 in 4,500-5,500 [5]. Data are not available to determine the exact frequency of specific DSDs, while only a small fraction of those with DSDs require extensive multidisciplinary assessment to reach a recommendation for gender assignment.

The incidence rate among subjects with $46, \mathrm{XY}$ to have a DSD has been estimated to be 1 in 20,000 births. Ovotesticular DSDs have been estimated to occur in 1 of 100,000 live births [6]. The frequency of testicular or mixed gonadal dysgenesis is estimated at 1:10,000 [7]. The worldwide incidence of 46,XX DSD, consisting primarily of CAH - mostly 21-hydroxylase deficiency -, has been estimated to be 1 in 14,000-15,000 live births [8], but it varies by regions because of ethnic differences in gene mutation frequency. CAH and mixed gonadal dysgenesis constitute about half of all DSD patients presenting with genital ambiguity [9].

When all congenital genital anomalies are considered, including cryptorchidism and hypospadias, the rate may be as high as 1:200 to $1: 300$ [10]. Among patients with hypospadias and cryptorchidism, currently the diagnosis of specific DSD conditions is generally limited to those with proximal hypospadias with cryptorchidism. The overall incidence estimations also include those with 
Klinefelter syndrome (estimated in 1:500 to 1:1000 live births) and Turner syndrome (about 1:2,500 live births). These known estimates hopefully provide a useful perspective.

\section{Support Groups}

The 2006 Consensus Statement [1] was a landmark for providers caring for individuals with DSDs and the larger community. Increasingly collaborative relationships are occurring in care settings and at national peer support group (PSG) meetings, reflecting growing prioritization of patient perspectives focusing on health and well-being outcomes. Community priorities for improvement have been identified, while disagreements regarding mutual goals for patient-centered research and care persist.

Peer support (PS) is a key component of the 20132020 WHO Mental Health Action Plan [11]. This relieves patients from isolation and provides a unique source of identity support, anticipatory guidance and medical information accessible to individuals of all levels, in keeping with the Consensus Statement's call for improved evidence and diagnosis-specific recommendations. Rather than the monolithic approach to treatment, community members now call for evidence-based interventions, the consistent inclusion of evidence and of controversies in informed consent processes and the creative identification of alternative strategies, including psychosocial support and PS as primary interventions.

Many PSGs are eager to collaborate in research focused on patient-centered outcomes, promoting highquality nonduplicative research through input into the research design and goals while limiting participant 'research fatigue' to improve recruitment. For example, the Androgen Insensitivity Syndrome (AIS)-DSD support group (SG) created a research policy that facilitates participation in projects if a SG medical advisor serves as project consultant [12]. Furthermore, clinicians could utilize PSGs as reservoirs of qualitative lived experience of patients and families to define an affirmative care model similar to the World Professional Association for Transgender Health (WPATH) standards of care for transgender individuals, emphasizing liberal referral to PS and psychosocial support [13].

Given the numerous current barriers/controversies including language, best practices and human rights organizations' positions on children's rights to self-determination (UN Intersex Fact Sheet: United Nations Office of Human Rights High Commissioner) [14], a patient- clinician forum like that organized in the early 2000s by the AISSG UK and University College London Hospitals (UCLH) [15] could provide a framework for an effective collaboration among PSGs, clinicians and other stakeholders.

The collaboration with existing PSGs is crucial for developing more support for specific conditions, for integrating PS into the model of healthcare and for encouraging patient-centered research. A 2014 study showed that several established PSGs already enjoy the involvement of clinicians, and that the overwhelming majority are receptive to closer relationships [16]. Cultivating relationships with these groups allows clinicians to access existing programs or to collaborate on new resources. Many PSGs provide an umbrella of support for multiple diagnoses, including condition-specific sessions at their meetings. PSGs may also be able to direct clinicians to unpublicized local resources and private social media groups. An updated comprehensive list of international PS and advocacy resources is included in table 1.

Local individuals who volunteer themselves in clinics or through PSGs can enhance the teams' psychosocial services, especially with standardized training. Besides integrating PS into clinical practice, the inclusion of an affected person as a resource on the care team ensures routine consideration of patient perspectives. The Children's Hospital in Denver, Colo., USA, is successfully piloting this model. Other helpful strategies are making volunteers available during clinic hours and including them in clinical conferences. In London, UK, PSGs participate in Clinic Open Days, which are sometimes condition specific, e.g. XY-female or Mayer-Rokitansky-Küster-Hauser (MRKH) syndrome, at UCLH. Patients have the unique opportunity to receive medical information from clinicians and to learn about PSGs from group representatives.

Routine incorporation of PS into clinical care at the earliest possible time can ease what can be a bewildering experience for parents. The discovery of reproductive variation or the delivery of a baby with genital difference can leave families feeling isolated, overwhelmed and immobilized. One of the most comforting things parents can hear is that differences of sex development are more common than most people realize, and that there are many families successfully raising children like theirs. Messages like 'We know this is challenging, but lots of families like yours are raising happy healthy children. May we share your contact information so one of them can get in touch?' can reduce distress and isolation. Relieving parents of the responsibility to initiate contact by having an experienced 
Table 1. PS and advocacy resources for DSD and intersex

Organizations based in Africa

MRKH (Mayer-Rokitansky-Küster-Hauser syndrome) https://www.facebook.com/MRKH-Africa-

Africa Foundation

Foundation-752051251535281/?fref=ts

East Africa

Androgen Insensitivity Syndrome Support Group

aissgeastafrica@gmail.com

(AISSG) East Africa

South Africa

Organization Intersex International (OII) South Africa http://www.intersex.org.za

info@intersex.org.za

- Intersex South Africa

South African Androgen Insensitivity Syndrome Support

Group (SAAIS)

Uganda

Support Initiative for People with Atypical Sex

Development (SIPD) - Uganda

https://www.facebook.com/SIPD-Uganda

Organizations based in Asia

Androgen Insensitivity Syndrome Support Group

http://www.aissg.org

uk@aissg.org

(AISSG Asia, UK, eastern Europe)

Bangladesh

MRKH (Mayer-Rokitansky-Küster-Hauser syndrome)

Bangladesh

China

Organization Intersex International (OII) China

http://www.oii.tw/

hiker@oii.tw

Japan

Androgen Insensitivity Syndrome - Differences of Sex

Development (AIS-DSD0 SG) Japan

Intersex Initiative

http://aissgjp.org/

support@aissgjp.org

Peer Support for MRKH Japan

http://intersexinitiative.org/

http://ps4mrkh.wix.com/peer-support-4-mrkh

info@intersexinitiative.org

Myanmar

AISSG-Myanmar

aissgmy@gmail.com

Philippines

OII Philippines - InterSex Philippines

https://www.facebook.com/IntersexPhilippines

Jonalyn V. Bulado: mobile number

+639277754317

Organizations based in Australia/New Zealand

Australia

Androgen Insensitivity Syndrome Support Group

(AISSG) Australia

Organization Intersex International (OII) Australia

Sisters for Love MRKH Foundation - Mayer-

Rokitansky-Küster-Hauser syndrome

New Zealand

IANZ Intersex Awareness New Zealand

http://www.aissga.org.au/

aissgaustralia@gmail.com

https://oii.org.au/

http://www.sistersforlove.org

https://oii.org.au/information/contact/

http://www.sistersforlove.org/contact.html

Organizations based in Europe

Organization Intersex International (OII) Europe

http://www.ianz.org.nz/

http://www.ianz.org.nz/contact/

http://oiieurope.org/

http://oiieurope.org/

http://oiieurope.org/about/contact//

contact/

Austria

OII Austria -VIMÖ | Verein Intersexueller Menschen http://vimoe.at/

info@vimoe.at

Österreich - Intersex People Austria

Belgium

OII Belgium - Genres Pluriels Asbl

http://www.genrespluriels.be/

contact@genrespluriel.be

Eastern Europe

Androgen Insensitivity Syndrome Support Group

(AISSG)

http://www.aissg.org

uk@aissg.org

Global Disorders of Sex Development

Update since 2006
Horm Res Paediatr 2016;85:158-180

DOI: $10.1159 / 000442975$ 
Table 1 (continued)

France

Association syndrome de Rokitansky - Mayer-

Rokitansky-Küster-Hauser syndrome (MRKH)

Germany

OII Germany

Intersexuelle Menschen e.V. - Intersex People German

Intersexuelle Menschen Self Help Group for Intersex

Adults

Intersexuelle Menschen Self Help Group for Intersex

Parents

Intersexuelle Menschen Self Help Group for XY Women

Intersexuelle Menschen Self Help Group for XY Parents

MRKH Syndrom
Iceland
OII Iceland - Intersex Ísland

Italy

Associazione Italiana Sindrome da Insensibilità agli

Androgeni

OII Italy - Intersexioni (AISIA)

The Netherlands

DSDNederland

Nederlands Netwerk Intersekse/DSD - OII Netherlands

Stichting MRKH

Norway

MRKH Norge

Russia

Association of Russian-Speaking Intersex People (ARSI)

Russian/Ukraine Мы райт Россия СРМК

Serbia

Gayten-LGBT, Center for Promotion of LGBTIQ

Human Rights - Serbia

Spain

AMAR - Asociación de Apoyo a Mujeres para la

Aceptación del Síndrome de Rokitansky: MRKH

GrApSIA - Asociación y grupo de Apoyo a favor de las

personas afectadas por el Síndrome de Insensibilidad a

los Andrógenos y condiciones relacionadas - AIS and

related conditions

Sweden

Intersexuella i Sverige - Intersex People of Sweden

http://www.inis-org.se/

kontakta@inis-org.se

Switzerland

AISSG-Switzerland

http://intersex.ch

kontakt@intersex.ch

United Kingdom

Androgen Insensitivity Syndrome Support Group -

AISSG

Children Living with Inherited Metabolic Diseases

(CLIMB) CAH Support Group

dsdfamilies.org

Intersex in the UK - OII UK

Intersexuk

Kallmanns.org - Kallman Syndrome and

hypohypogonadotrophic hypogonadism

info@amar-mrkh.org http://www.aissg.org

http://www.livingwithcah.com/

http://www.dsdfamilies.org

http://oiiuk.org/

https://www.facebook.com/

KallmannSyndrosme/http://www.kallmanns.org/ https://www.facebook.com/ intersexuk http://www.intersexualite.de/

http://www.intersexuelle-menschen.net/

kontakt-und-impressum/

vorstand@intersexuelle-menschen.net

(t//www.intersexuelle-menschen.net/switch-_ info@shg.intersexuelle-menschen.net

http://www.intersexuelle-menschen.net/switch-

shg.php

info.eltern@shg.intersexuelle-menschen.

net

shg.php

http://www.intersexuelle-menschen.net/switch- info.eltern@xy-frauen

xy.php

http://www.mrkh-syndrom.net/_ InesR@gmx.at

http://intersex.samtokin78.is/

http://www.aisia.org

info@aisia.org

http://www.intersexioni.it/

info@intersexinitiative.org

http://www.dsdnederland.nl

http://www.dsdnederland.nl/contact/

algemeen-contact

http://nnid.nl/contact/

http://www.stichtingmrk.nl/

http://mrkhnorge.no

mrkh@mrkhnorge.no

https://www.facebook.com/ groups/

intersex2013/

http://rokitansky-syndrome.jimdo.com

http://www.transserbia.org/

gayten@gmail.com

http://www.amar-mrkh.org/

http://www.amar-mrkh.org/p/sobre-amar.html

http://grapsia.org/

grapsia@gmail.com uk@aissg.org

http://www.livingwithcah.com/contact.

html

info@dsdfamilies.org

http://oiiuk.org/contact/

http://kallmanns.org/contact 
Table 1 (continued)

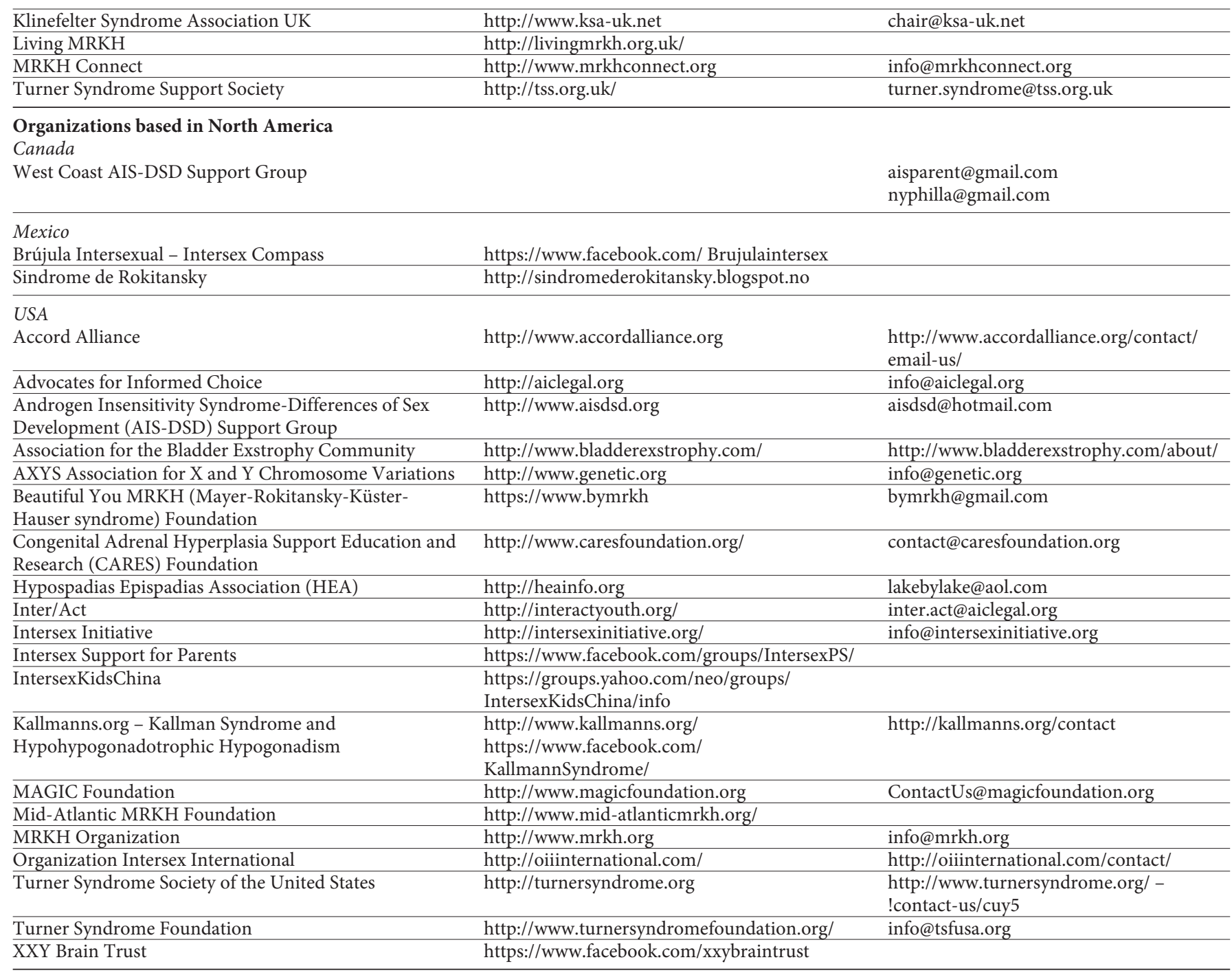

\section{Organizations based in South America}

Argentina and Colombia

GrApSIA - Asociación y grupo de Apoyo a favor de las personas afectadas por el Síndrome de Insensibilidad a los Andrógenos y condiciones relacionadas - AIS and related conditions

Based in Spain with contacts in South America

Argentina: grapsiaargentina@gmail.com Colombia: grupoapoyoorg@gmail.com

Chile

Ninfas de Rokitansky

http://ninfasderokitansky.blogspot.no/

family reach out removes the stress of having another unknown to deal with. While they await contact, families can be directed immediately to PSGs and other resources with reassuring information, such as $d s d$ families.org and the Handbook for Parents (www.accordalliance.org/ dsdguidelines/htdocs/parents/).

Global Disorders of Sex Development Update since 2006
Researchers often contact PSGs for help recruiting participants in studies that are already IRB (institutional review board) approved; on the other hand, PSGs have found that they can be extremely effective in supporting the development of research that meets the needs of affected communities when involved from the inception of research in the design of methods and goals, when able to 
give input into sensitive language and when engaged to ensure that the specific concerns of the community regarding human research ethics are addressed. A suggested collaborative model that has proved successful in improving models of care in conditions such as breast cancer is community-based participatory research (CBPR), in which patient advocates, clinicians and researchers collaborate in the design of research [17]. One goal of a stakeholder forum might be the development of a community-based participatory research project to create surveys of patient priorities for care and research. Stakeholders' openness to use a mix of methods might resolve historical differences on issues as basic as the value of quantitative versus qualitative evidence. For example, a narrative analysis may reveal themes such as emotional openness or resilience that could lead to studies of effective psychosocial interventions [18].

\section{Clinical Evaluation}

The clinical evaluation of a child with atypical or ambiguous genital development begins with a thorough history and physical examination [19]. The management of a patient with a DSD involves a team approach to arrive at a definitive diagnosis based on available data [20].

Many individuals with a DSD are recognized in the newborn period, when ambiguous genital development is noted on the infant's first physical examination. In some instances, discordance between the prenatal karyotype, the prenatal ultrasound report and the newborn's genital appearance prompts an evaluation. Later presentations can occur in children, adolescents and adults. Examples of clinical findings associated with later presentation include progressive clitoromegaly, inguinal/labial mass(es) in a phenotypic girl, delayed or incomplete pubertal development, progressive pubertal virilization in a phenotypic girl and cyclical hematuria in a phenotypic boy.

For all patients, especially infants, a thorough prenatal history should be obtained. The medical history for older children includes questions pertaining to presence and timing of genital and pubertal development. Was the mother exposed to any known teratogens, potential environmental disrupting agents or medications? Are there other family members with atypical genital development in the family? Did any unexplained deaths occur in the family? Probing for consanguinity may be helpful especially when an autosomal recessive disorder is being considered in the differential diagnosis. A detailed family history regarding fertility of the grandparents, aunts and uncles may be helpful particularly in families with complete AIS.

The prenatal diagnosis of DSD has become more frequent with increased fetal monitoring during pregnancy. Improved ultrasound technology has made it possible to visualize the genitalia. Prenatal karyotyping has enabled the detection of sex chromosome mosaicism and discrepancies between chromosomal sex and phenotypic sex, either with prenatal ultrasound or at the birth of the child. A retrospective review suggests that prenatal genetic testing is not practical for rare DSD conditions without a family history and that prenatal karyotyping with fluorescent in situ hybridization (FISH) is the most useful when ambiguous genitalia are suspected [21].

\section{Evaluation of an Infant with Ambiguous Genital Development}

The initial physical examination should be meticulous, organized and unhurried. Anthropometric features should be assessed as well as vital signs. The facies, limbs and digits should be carefully examined for dysmorphic features. Skeletal features associated with Antley-Bixler syndrome suggest POR deficiency, whereas campomelic dysplasia suggests SOX9 mutations [22]. Midline facial/neural defects and/or optic nerve hypoplasia suggest the possibility of one or more pituitary hormone deficiencies [23].

The examination of the external genitalia starts with observation to ascertain whether the external genital structures are symmetric or asymmetric. The degree, if any, of labioscrotal hyperpigmention should be gauged. Careful palpation is necessary to establish whether gonads are present in the labioscrotal folds, inguinal area or nonpalpable. Bilateral nonpalpable gonads raise suspicion that the infant is a virilized female with CAH. Asymmetry of the external genitalia, i.e. a unilateral palpable gonad, may indicate gonadal dysgenesis associated with a 45,X/46,XY karyotype. Transverse testicular ectopia indicates persistent Müllerian duct syndrome.

Insufficient testosterone concentrations in a 46,XY fetus during the critical window of male sex differentiation are typically associated with a spectrum of external genital development ranging from apparent female to ambiguous [23]. The length and diameter of the phallus need to be assessed. The position of the urethral meatus must be located. The urethral meatus may be present in its usual location on the glans penis, along the shaft of the penis or on the perineum. It is important to determine whether there is a single perineal opening representing a urogeni- 
tal sinus. Although it has been suggested that the anogenital distance may provide information regarding prenatal androgen exposure, delineation, precision of measurements and lack of normative values hinder the use of this measure [24]. Rather, an external masculinization score can be calculated on the basis of scrotal fusion, phallic length, position of the urethral meatus and location of the gonads [19].

Some infants present with a global developmental field defect such as cloacal anomalies, anorectal malformations or bladder exstrophy-epispadias complex anomalies [25]. The absence of the anal opening indicates an underlying anorectal malformation that may be associated with additional anomalies such as the VATER or VACTERL associations [26]. Penoscrotal transposition with hypospadias and aphallia/penile agenesis represent primary developmental anomalies of the external genitalia. These infants show an abnormal external genital anatomy that cannot be easily categorized according to the Prader scoring system [26]. These disorders are typically associated with normal gonadal development and function.

\section{Evaluation of an Adolescent}

During adolescence, patients with DSD can present with primary amenorrhea or progressive virilization in a phenotypic girl. Has there been progressive clitoromegaly? The adolescent may present with delayed or incomplete pubertal development. Sensitivity to privacy needs, emotions and cognitive function is essential when evaluating and treating an adolescent. The diagnosis of a DSD may devastate an adolescent's personal identity and selfesteem and alarm the family.

A comprehensive physical examination including anthropometric features, blood pressure measurements and the evaluation for dysmorphic features is appropriate. Individuals with a 45,X/46,XY karyotype may have clinical features typically associated with Turner syndrome [27]. Wilms' tumor may be the presenting feature for DenysDrash syndrome associated with WT1 mutations. Secondary sexual characteristics including the presence/absence of breast development, the extent of sexual hair, symmetry of external genital structures and the size/development of the clitoris/penis need to be ascertained. The palpation of the labioscrotal folds and inguinal areas is important to ascertain for gonads. Small firm testes accompanied by learning difficulties and tall stature are clinical features suggestive of Klinefelter syndrome [28].
Females with MRKH syndrome generally present with normal breast development and primary amenorrhea; they may have associated renal and vertebral anomalies.

\section{Biochemical Evaluation}

Hormone measurements need to be interpreted in relation to the specific assay characteristics and to normal values for gestational and chronological age. In some cases serial measurements or stimulation tests may be needed.

\section{Which Newborn/Infant Should Be Investigated and}

How Extensively?

An extensive investigation is required when the external genitalia are sufficiently ambiguous to hamper sex assignment or inconsistent with the results of prenatal tests.

The first-line testing in newborns includes measuring 17-hydroxyprogesterone (17-OHP) and serum electrolyte, androgen, anti-Müllerian hormone (AMH) and gonadotropin levels, together with investigations to define the sex chromosomes. Serum 17-OHP is usually unreliable before the age of $36 \mathrm{~h}$, and in the salt-losing form of $\mathrm{CAH}$, serum electrolyte levels usually do not become abnormal before day 4 of life.

Steroid hormone determination should be performed after an extraction or chromatography to avoid concerns of analytical specificity $[29,30]$. Serum levels of testosterone are low in the normal male newborn during the first 7-14 days of life [30], and increase progressively thereafter until the age of 2-3 months [30,31], thus results should be interpreted in that context. Gas chromatography or liquid chromatography linked with tandem mass spectrometry (GC/MS or LC-MS/MS) allows multiple analyte analysis from a single sample while maintaining specificity $[32,33]$.

The existence of testicular tissue can be assessed by serum $\mathrm{AMH}$ determination [34]. Although AMH is expressed by both testicular Sertoli cells and ovarian granulosa cells, AMH is detectable at birth at much higher circulating concentrations in boys than in girls [30]. With these tools, an initial diagnosis can be reached. In 46,XX newborns, elevated 17-OHP and androgen levels are distinctive of $\mathrm{CAH}$, with hyponatremia and hyperkalemia in salt-wasting variants. With the availability of genotyping, a salt-losing crisis is no longer required for the diagnosis of this variant. When androgen and $\mathrm{AMH}$ values are above the female range, ovotesticular DSD is likely, whereas when androgen values are elevated but AMH is in the normal female range, aromatase deficiency should 
be suspected. If androgen levels decrease progressively, together with the degree of virilization, maternal virilizing tumors could be the source [35]. In Y chromosomebearing newborns, low AMH and androgen levels are indicative of dysgenetic gonads, low androgen values and normal/high AMH suggest steroid production defects, and normal/high AMH and androgen values are characteristic of androgen insensitivity or nonendocrine malformative DSDs [35, 36]. Gonadotropin levels may also be helpful, since they are usually very high in dysgenetic DSDs and normal or only slightly elevated in steroid synthesis defects and partial androgen insensitivity. They can even be low in patients with complete AIS [37].

Further biochemical tests are needed to clarify the etiological diagnosis in newborns or infants with isolated perineal hypospadias, isolated micropenis, isolated clitoromegaly, any form of familial hypospadias and those who have a combination of genital anomalies with an external masculinization score $<11$ [19]. In addition to repeated measurements of basal AMH and androgen levels, decision-making algorithms include hCG and ACTH stimulation tests to assess testicular and adrenal steroid biosynthesis and urinary steroid analysis by LC-MS/MS, together with imaging studies and a biopsy of gonadal tissue.

Basal AMH and androgen levels are indicative of the mass of functional Sertoli and Leydig cells. Their levels may range from very low in XY patients with severely dysgenetic gonads or XX patients with ovotesticular DSDs with predominant ovarian tissue to normal male values in mildly dysgenetic DSDs or ovotesticular DSDs with abundant testicular tissue. Since AMH and androgens levels are normally low in the male newborn and increase progressively after the third week of life [30,38], repeated measurements may be needed.

Prolonged hCG stimulation may be necessary in some cases to assess defects of steroidogenic proteins [39, 40], although this should only be done after careful consideration as there may be negative effects upon the testes. An ACTH test may help when a steroidogenic defect affecting both the gonads and the adrenals is suspected.

\section{Which Adolescent Should Be Investigated and How}

Extensively?

Adolescents may typically present with a suspected DSD as girls with primary amenorrhea (with or without breast development) or with signs of virilization. In 46,XY girls with breast development and primary amenorrhea, elevated androgen and AMH levels and an absent uterus, complete androgen insensitivity is most likely [35]. If there is no breast development, severe Leydig cell-specific steroid synthesis defects may be the cause. Extremely low levels of all gonadal steroids are indicative of LH receptor mutations, whereas low testosterone levels with elevated androstenedione values suggest $17 \beta$-hydroxysteroid dehydrogenase type 3 (17 $\beta$-HSD3) deficiency. The appearance of clitoromegaly and hirsutism at puberty in the presence of primary amenorrhea may be due to $17 \beta$-HSD3 or $5 a$-reductase type 2 deficiency and less typically to partial AIS; some degree of ambiguous genitalia may have been noticed at birth in these cases. In 46,XX ovotesticular DSDs, the signs of virilization, which may have been overlooked at birth, are suggestive of the existence of testicular tissue. The differential diagnosis would include $\mathrm{CAH}$ and androgen-secreting tumors of the ovary or adrenal gland. $\mathrm{AMH}$ and testosterone levels are above the female range. A 24-hour urine collection for a urinary steroid profile will confirm CAH or adrenocortical tumor $[33,41]$.

\section{Genetics}

The development of rapid diagnostic tools are enabling better diagnoses/classifications and provide for a better understanding of DSD conditions, better genetic counseling, assessment of reproductive options and more precise outcome studies.

New genetic and genomic technologies are expanding our knowledge of the underlying mechanisms of DSDs and open novel clinical diagnostic strategies. At patient presentation, the current approach is to (a) search for additional phenotypic information, including urgent metabolic and endocrine testing and imaging studies; (b) rapidly identify the sex chromosome complement by karyotype analysis or FISH with $\mathrm{X}$ and $\mathrm{Y}$ probes and chromosome microarray, and (c) test for copy number variants in regions associated with known DSD genes. Gene sequencing, either of single candidate genes or a gene panel, based on information gleaned from previous phenotypic investigations, is often the last step of the diagnostic process.

Only limited numbers of the many identified genes involved in sex development are currently available for clinical testing. The current standard for genetic diagnosis is sequencing a small number of known DSD-causative genes chosen as likely candidates based on disease phenotype. Large numbers of patients do not receive a clinical molecular diagnosis using this narrow scope, and it is assumed that many DSD-causative genes remain to be identified. 
An alternative diagnostic approach could use nextgeneration sequencing (whole exome or whole genome sequencing) as a first-line clinical test and lead to a rapid and definitive diagnosis in the majority of cases. However, this approach is faced with hurdles including long turnaround times, high costs, a lack of insurance approval or national healthcare system coverage and difficulties in the interpretation of the results, such as questions about reporting of nonrelated incidental findings or sequence variations which are significant but not recognized as such. These obstacles are likely to be overcome in the future, and next-generation sequencing is likely to become one of the first methods used for the diagnosis of DSD.

Currently, in instances in which a genetic diagnosis and the risk of recurrence are known, there is the possibility of prenatal diagnosis in subsequent pregnancies.

A review of human sex determination genetics has recently been published [42]. The complexity of genetic regulation, even with advanced technology to identify mutations and copy number variations, is insufficient to explain the observed phenotypes. Genetics alone remains unable to explain the biological and psychological issues related to individuals with DSDs.

\section{Advancing and Evidencing Psychosocial and Psychosexual Well-Being}

The psychological aspects of DSDs have either been narrowly conceptualized as brain gender research [43] or as a 'catch-all concept' incorporating any broad social or psychological concepts [44]. An emergent conceptualization is evident in the 2006 Consensus Statement: 'Psychosocial care provided by mental health staff with expertise in DSD should be an integral part of management to promote positive adaptation. This expertise can facilitate team decisions about male or female assignment/reassignment, timing of surgery, and sex-hormone replacement.' [1]. Psychological interests have broadened, but require conceptual clarity [45]. Reported research has weaknesses [46]. Methods are suggested below to facilitate future applied psychosocial research. Currently, wellbeing is defined as scores on popular quality of life (QoL) scales. Any causal link between a diagnosis and a single psychometric measure is flawed [47], since the effects of a diagnosis on well-being depend on a wide range of intrinsic and extrinsic factors across time including physical health, age, social values and access to resources including work, education, supportive relationships and health-care experiences. Well-being may be affected in highly specific ways at certain times, such as at the initial diagnosis, during the developmental stage, at symptom control, during fertility treatment or at the beginning and end of an important relationship.

Psychologically informed research with adults using a wider range of methods has captured specific difficulties, often despite medical interventions, such as dissatisfaction with binary gender [48], dissatisfaction with the DSD terminology [49], fear of devaluation [50], negative body image [51], social isolation [52], non-entitlement to relationships [53], preoccupation with heterosexual intercourse [54], functional sexual difficulties [55], barriers to communication with significant others and experiencing normalizing surgery as dilemmatic [56]. These studies have highlighted salient experiences and numerous potential mitigating factors which impact long-term outcome.

It has been hypothesized that body differences associated with DSDs may harm well-being although inconsistently. The high prevalence of normalizing surgery makes it impossible to separate the psychosocial impact of body differences and surgical management. In some cohorts, adults' dissatisfaction with their early surgery is high [57], while others report more positive long-term outcomes $[58,59]$. Parental awareness of management options and consequences of decision making due to inadequate information are important topics [60].

Affected people make daily decisions about managing differences in the social sphere. It is unclear how self-disclosure relates to well-being, a concern of most care users. Minority stress (chronically high stress levels faced by members of stigmatized minority groups) research and studies of the impact of advocacy groups to mitigate distress have not been applied in DSD studies [16]. Advocates and clinicians recommend team and communication skills training for health professionals to advance well-being [61].

Group psychological interventions can improve wellbeing for women with MRKH syndrome [62], and group cognitive behavioral therapy can reduce specific stresses [63]. Group work drawing on cognitive and narrative approaches appears to improve self-evaluation of women with Turner syndrome [64].

A broader methodological approach is required [65], using a combination of existing methods that are highly relevant [66]. The open-endedness of qualitative approaches offers a greater scope for participants to define their own challenges and articulate emotions. With the emergence of well-designed and properly conducted nation-wide studies, methodology may become less constrained by the scarcity of research participants and hope- 
fully benefit from more thorough epistemic considerations.

It is recommended to build on the small body of work using mixed methods, drawing on communication, organizational development, social studies and applied healthcare psychology research.

\section{Evolving Perceptions: Male or Female Assignment, Reassignment and Outcome}

The following is caretaker focused, while delaying decision options and involvement of the patient are discussed in the Ethical, Legal and Cultural Issues section.

There are ongoing debates after the incorporation of some individuals with DSDs under the psychiatric diagnostic category of gender dysphoria [67] including those dissatisfied with their male or female assignment. The construct of gender identity itself and related theories of gender identity development recognize a higher degree of complexity hopefully better representing biopsychosocial reality than previously [68].

The concept of 'gender identity' is a psychological one and poses a number of challenges for the clinician. In recent years, several tools have been developed for the systematic assessment of gender identity that aim at both the characterization of individuals in terms of gender categories within the primary binary gender system with its additional niches or categories and also in terms of a dimensional gradation of gender identity, usually on a bimodal continuum [69]. In the presence of significant intrafamilial and/or societal stigmas associated with gender-identity atypicalities, some individuals may keep private their gender dysphoria or the incongruence of their self-perceived gender identity with their assigned gender [e.g., 70]. A biomarker of gender identity is not (yet) available. Although a number of studies have published differences in central nervous system (CNS) structures between transgender and cisgender adults [71], these studies use a variety of brain-imaging (or cadaver-sectioning) techniques; the findings are heterogeneous and lack replication; and where there are structural differences, they usually overlap to a considerable degree between transgender and cisgender samples, so that they are not yet useful for individual gender categorization. Moreover, our current knowledge of the structures and functions of the CNS underlying gender identity is insufficient to read MRIs for the presence of a specific gender identity. Even if at some point in the future such an interpretation of MRI findings should become possible for individuals at later stages of cognitive development, it is questionable that the brain of a newborn is developed enough for the prediction of gender identity years later, given the gradual development of critical sex-dimorphic aspects of the CNS [72].

Considering newborn male or female assignment, there is increasing evidence, especially for $46, \mathrm{XX}$ individuals with DSDs and when gender identity is assessed dimensionally rather than in terms of binary categories, that prenatal androgen levels have effects on human gender-related behaviors including sexual orientation and gender identity [73-75]. Those without fetal exposure (complete AIS or 46,XY complete gonadal dysgenesis), born with female-appearing external genitalia assigned female maintain that gender on long-term follow-up with rare exceptions [76]. Genital status at birth is moderately correlated with summary scales of later gender-related behavior, but not at all in syndromes involving nonhormonal malformations such as cloacal exstrophy or penile agenesis. Moreover, postnatal androgens, both in early infancy [77] and at later stages, may also contribute to long-term gender outcome. This is presumably mediated through organizational effects on the developing brain as well as the psychosocial effects of somatic virilization. Virilization may impact self-image and lead to negative social reactions, as seen in poorly controlled $46, \mathrm{XX} \mathrm{CAH}$ patients, untreated $46, \mathrm{XY} 5 \mathrm{a}$-reductase deficiency patients and $17 \beta-H S D 3$ deficiency patients [78].

For most patients presenting with genital ambiguity so severe that a multidisciplinary group is needed to consider male or female assignment, the Consensus Conference summary [1] made the following recommendations. Female assignment is suggested for those with (1) 46,XX and $\mathrm{CAH}$, since $95 \%$ develop female gender identity; (2) complete AIS, and (3) 46,XY LH receptor deficiency. Male assignment is recommended for those with $5 a-$ reductase deficiency, since $60 \%$ later identify themselves as male, and for $17 \beta$-HSD3 deficiency, since $>50 \%$ later switch to male. The suggested assignment for ovotesticular DSDs was as discussed below, with similar approach for mixed gonadal dysgenesis.

Overall factors to be considered for male or female assignment included probable adult gender identity (considered most important, but only tentatively predictable), anticipated quality of sexual function, surgical options/ indications/risks, fertility potential, evidence of fetal CNS exposure to androgens, gonadal malignancy risk and psychosocial factors (familial, social and cultural). While most difficult to predict, the anticipated quality of sexual function is a key factor. Evidence suggests that this may not be influenced so much by genital anatomy as other 
less tangible factors, related to interpersonal relationships. Among women with $\mathrm{CAH}$ [79], the ability to achieve an orgasm is not correlated with sensitivity, and neither this nor satisfaction with sexual life are different from control women. Hence, neither the anatomy nor a consult with sexual medicine can predict the quality of sexual function, since it depends upon interpersonal dynamics and the individual's abilities to participate and respond during sexual situations.

Sexual function scores were higher in patients satisfied with their sexual lives and with their surgical result [79]. Discrepancies were noted between CAH women's perception of the impact of their condition on their lives and what health professionals assumed based on clinical examination. The more severely affected (having the null genotype) scored lower on both sex function and sexual life satisfaction. In another report from the same study cohort, the psychological general well-being did not differ from that of the control group [80]. However, more CAH women, particularly those in the null genotype group, had male-dominant occupations, a greater interest in rough sports and motor vehicles. Nonheterosexual orientation occurred more frequently in the more severe genotype groups. The higher incidence of problems, particularly in those with severe CAH (like the null genotype group), may help to inform gender decision making in the severely virilized CAH infant. While sexual orientation should not be considered as a marker of favorable outcome, the higher incidence of nonheterosexual orientations in these patient subtypes suggests an important trend of the influence of fetal androgen on outcomes.

Patient care should be individualized even within clear etiologic diagnostic categories. For example, among 46,XX patients with CAH with Prader 4 and 5 genitalia at birth, available outcome data from patients raised male with follow-up well beyond midlife suggest for those essentially fully masculinized in utero that a male assignment be considered when social and cultural environment are supportive. 46,XX newborns with marked genital masculinization are more likely to show marked masculinization of behavior. This in combination with the risks of feminizing genital surgery to cosmesis and sexual functioning have led to a call for consideration of male rearing of these newborns [81].

The previously widespread routine assignment of 46 , XY newborns with markedly hypomasculinized genitalia as females has given way to more detailed considerations of biological factors involved in combination with gradually increasing evidence for syndrome-specific long-term outcomes. Physicians are now more likely to suggest male assignment of 46,XY newborns who presumably had normal-male prenatal androgen levels with nonhormonal genital malformations, such as cloacal exstrophy of the bladder or penile agenesis $[82,83]$. Evidence-based recommendations taking into account genital variables need to consider both gender-identity and QoL outcomes for male or female sex of rearing.

While there has been a trend to assign most $46, \mathrm{XY}$ patients with DSDs as male [83], individualized caution must be taken with male assignment based on evidence of androgen responsiveness and CNS androgen exposure during fetal life. Although $60 \%$ of all $46, \mathrm{XY}$ patients with $5 a$-reductase deficiency develop a male gender identity, there are reports of those assigned female with satisfactory sexual activity [84]. Hence, individual male or female assignment should be based of physical development, hormonal secretion, the presence/absence of genetic mutation and the response to hormonal therapy, particularly DHT. Among those with partial AIS, male assignment should be based upon a demonstrable response with phallic growth to testosterone therapy and genetic assessment if a causative variant of the gene is found, while female assignment must be considered for those without evidence of androgen effects. For those with 46,XY with $17 \beta$-HSD3 deficiency, care must be taken to assess all aspects, since there is evidence of satisfactory sexual function both among those raised male and those raised female. Among those raised male, there is considerable penis length dissatisfaction, and among those raised female, there is clinical distress. For those with $46, \mathrm{XY}$ and a micropenis, male assignment is preferable for most regardless of penis size except for those with partial AIS. Among men with 46,XY and noncategorized hypospadias, the overall body image and psychosexual functioning do not differ from controls, while those with surgically repaired hypospadias reported less satisfaction than controls with penile cosmetic appearance with differences related to hypospadias severity (more proximal). A subset of patients with hypospadias and those with a micropenis have an insufficient penile length to achieve penetrative intercourse, hence, the issue of adequate penis size persists. It is clear that the same care plan cannot be applied to all individuals with a given diagnosis/syndrome and severity; each must be carefully individualized with specific assessment of each aspect. Since genital appearance and function dissatisfaction may jeopardize sexual QoL, psychological support is strongly recommended.

Bias in gender decisions and the urgent need for evidence-based consensus are illustrated by assignments of infants with ovotesticular syndrome, about half of whom 
are assigned male or female regardless of karyotype [85]. The location of the urethral meatus and associated surgical challenges, dysgenetic testicular tissue and the presence of a uterus and normal ovarian tissue influenced the assignment in the past [86]. Case studies report gender dysphoria and/or patient-initiated gender change in either direction in patients $[87,88]$. For this condition and others, only systematic large long-term gender outcome and QoL data will constitute a solid empirical basis for determining crucial factors involved in assignment decisions. This will likely include the realization that all with the same etiological diagnosis and karyotype will not necessarily have the same male or female assignment.

\section{Information and Decision Making Regarding Male or Female Assignment}

Historically, health professionals - primarily physicians - did not openly and fully communicate with patients and families about their DSDs, in part because of the belief that there would be difficulties accepting a full disclosure. Without complete information, parents and eventually the affected person had an inadequate understanding about DSDs and their specific diagnosis. Now, it is clear that open and complete communications are mandatory when there is uncertainty in decision making. Education and psychological support regarding the impact are needed for each individual to make sense of the condition, relate to their community and establish relationships.

The lack of outcome data and different preferences make it difficult to determine whether and when to pursue gonadal or genital surgery. Shared decision making is necessary and can be viewed as the 'crux of patient-centered care' [89], combining expert health-care knowledge and the right of a patient or surrogate to make fully informed decisions. This entails a process of education, sharing of risks/benefits, articulating the uncertainties in DSD care and outcomes and providing time for the patient and family to articulate back the risks and benefits of each option. The goal of all involved should be to individualize and prioritize each patient.

There are efforts to improve clinical communication, including E-learning and prepared scripts that help physicians practice sharing information with patients and their families about a diagnosis [90]. Some clinics incorporate former patients and patient advocates to support families and patients. PSGs are dedicated to serving individuals. Educational materials have been created and can be found at www.dsdfamilies.org, www.interactyouth. org, www.dsdgenetics.org and www.accordalliance.org as well as other advocacy and SGs (table 1). An ongoing project of clinics and patient advocates within the USbased DSD-Translational Research Network is to develop a customizable list of educational material to provide to children, youth, families and adults in their clinics and make the sharing of resources more systematic in DSD teams.

Decision aids and support tools (DASTs) can enhance decision quality by increasing knowledge and understanding, promoting confidence in decisions and reducing decisional regret. A web-based DAST for parents of newborns or young children with DSD is currently being developed [91].

Continued efforts in effective communication also include viewing DSDs as similar in some aspects to other complex care situations, thereby allowing the incorporation of lessons learned from research and the continued efforts to improve collaborative work between researchers, clinicians and advocacy groups.

DSD health-care teams, developed largely since 2005, can be multidisciplinary, interdisciplinary or transdisciplinary, implying different degrees of collaboration and professional autonomy [92]. Multidisciplinary involves simultaneous, but independent, contributions of team members from two or more disciplines (fig. 1a). Team members in the interdisciplinary model work jointly, each from a discipline-specific perspective, but with acceptance that elements of knowledge and skills are shared to address a common problem (fig. 1b), thereby reducing turf battles. Finally, a transdisciplinary approach synthesizes discipline-specific concepts, creating new models to address a common problem. A cardinal feature of the transdisciplinary approach is that providers from all disciplines are jointly responsible for every clinical goal (fig. 1c).

As with other chronic conditions diagnosed during pediatric years, the transition of individuals with DSDs to adult care is not ideal. With limited exceptions, persons with DSDs may not, in the short-term, experience negative consequences from poor treatment adherence or avoidance of providers. However, such avoidance places the person at risk for long-term complications such as osteoporosis, gonadal malignancy, and poor psychosocial and psychosexual adaptation. The practice of withholding medical history details, along with the possibility of negative medical experiences, likely contributes to patients with DSDs frequently being 'lost to follow-up.' 


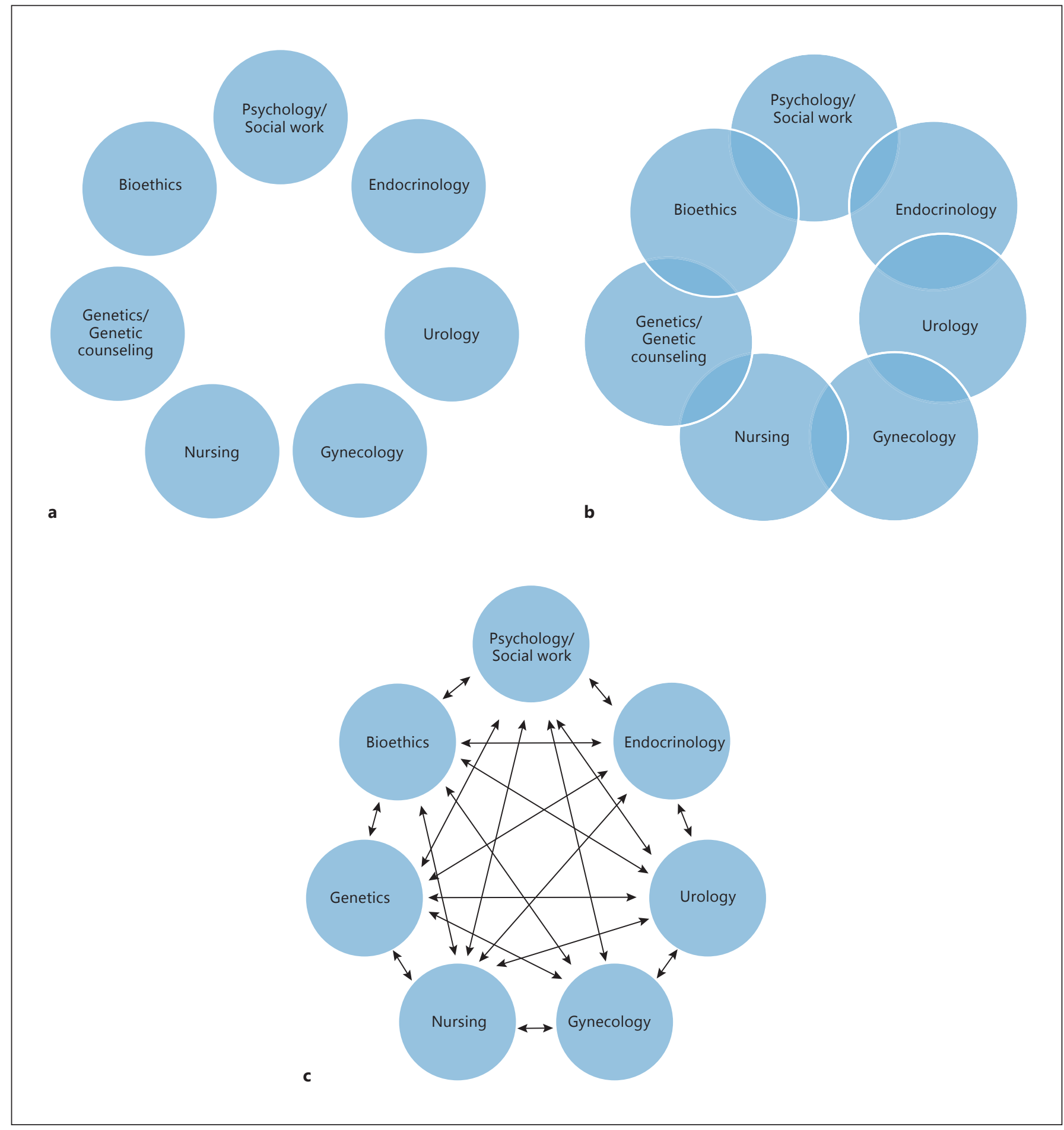

Fig. 1. Models of DSD team care: a simultaneous independent contributions of team members from two or more disciplines; $\mathbf{b}$ team members work jointly, each from a discipline-specific perspective, with acceptance that elements of knowledge and skills are shared to address a common problem; $\mathbf{c}$ a transdisciplinary approach syn- thesizes discipline-specific concepts, creating new models to address a common problem with all disciplines being jointly responsible for every clinical goal. Based on Institute of Medicine Report [77]. 
Other challenges for adolescents and young adults with DSDs include anticipatory anxiety related to romantic and sexual relations because of an atypical genital anatomy, function or infertility, and fears of stigmatization. Patient education in a developmentally sensitive manner is essential to facilitate an optimal medical and psychological follow-up [93]. Although adolescents may be reticent regarding their contact with patient support organizations, the potential benefits of speaking with others who have shared experiences should be reintroduced if initially rejected [16]. Guidance on preparing adolescents and young adults with chronic conditions for transition to adult care, in general [94] and specifically in DSDs [95], is available.

\section{Hormonal Treatment of Patients with DSDs}

With the exception of therapy for $\mathrm{CAH}$, hormonal treatment primarily involves pubertal induction for hypogonadism, hormone replacement therapy (HRT) at various ages and, in some instances, pubertal suppression. Patients with DSDs lacking functional gonads require HRT during adolescence to re-enforce gender identity, promote congruent secondary sexual characteristics, growth, bone health and psychosexual and social wellbeing. Pubertal induction is usually at age 10-12 in girls and 11-13 in boys, depending on the maturity, desires and informed consent of the patient and parents. Options for hormonal treatment for patients with DSDs are limited by practical considerations, such as pharmacokinetic properties and effectiveness of steroid hormone preparations, and availability.

Cultural factors also influence parents' and patients' expectations and desires for these treatments. A definitive diagnosis based on biochemical and genetic data enables providers to counsel the family about the natural history of the condition and may help inform decisions about therapy. Best practices to ensure that the chosen treatments lead to high patient satisfaction are needed. Such should include recommendations concerning monitoring of therapy with hormone and bone density measurements.

For pubertal induction in individuals with a female gender identity and a uterus, the standard approach remains a low dose of estrogen, gradually increasing the dose over 2-3 years mimicking the normal tempo of puberty. A slow titration of estrogen is especially important in patients in whom stature is of concern, i.e. Turner syndrome. All preparations are not available in all countries.
A recent trend is to use estradiol, which can be measured in serum to adjust dosing, rather than equine or synthetic estrogens. The disadvantage is that the bioavailability of oral estradiol ( $0.5-2.0 \mathrm{mg} /$ day) is highly variable. Compared to equine estrogens and ethinyl estradiol, the use of transdermal estradiol patches appears to be more physiological and consistent, by avoiding a first pass through the liver and allowing estradiol levels to be titrated to the mid-normal range for Tanner stage. Transdermal estradiol doses start at $6 \mu \mathrm{g} /$ day and are increased gradually over 3 years to $25-100 \mu \mathrm{g} /$ day, based on estradiol levels and clinical response. After 1-3 years of estrogen or the occurrence of break-through bleeding, medroxyprogesterone $5-10 \mathrm{mg}$ /day or micronized progesterone $200 \mathrm{mg} /$ day for 10-14 day/month facilitate menses in patients with a uterus. Pubertal induction in those with a female identity who do not have a uterus typically follows a pattern of escalating estrogen doses similar to that of girls with a uterus. However, in the absence of a uterus, no progestin is required. Some women are trying testosterone in addition to estrogen, although no clinical trial results are currently available.

For induction of male puberty, a variety of regimens are available. Testosterone ester injections have been used successfully for decades, given in frequencies of every 1-4 weeks. One regimen involves starting with $50 \mathrm{mg}$ monthly, advancing the dose every 6-12 months, and eventually reaching $100 \mathrm{mg} /$ week or $200 \mathrm{mg}$ twice monthly for the full adult dose. Testosterone undecanoate can be injected every 10-12 weeks. Transdermal patches and gels are now available and may provide more physiological daily exposure without peak-and-trough cycles. There is no evidence for their superiority over injections, and the gels may fail to produce testosterone values in the normal male range. Many have found that patches and gels are not popular because of the frequency of application, time required and reactions such as itching with the patches. Topical dihydrotestosterone, where available, is being tried for patients with $5 a$-reductase deficiency, although its efficacy has not been well documented. Long-acting depot formulations, primarily testosterone undecanoate, might offer the unique advantage of stable serum testosterone levels with injections every 10-12 weeks, but data are limited in adolescents. There is also some experience with testosterone pellets.

Gonadotropin-releasing hormone antagonists are being tried in contrasexual puberty to delay changes in patients with functional gonads whose gender identity is either uncertain or incongruent with the gonadal hormones. Under these circumstances, HRT and surgery 
should commence only after a full psychological evaluation at the appropriate age for each fully informed patient.

Once patients become mature, the choice of hormones, doses and schedules should fit the patient's needs and optimize long-term outcomes, including bone density, mental health, metabolic state, QoL and sexual satisfaction as well as interest in fertility and potential for assisted reproduction techniques.

Optimal replacement therapies for patients with gonadal failure beyond age 50 are not known. Estrogen replacement in symptomatic menopausal women is conventionally continued for approximately 5 years and then tapered, suggesting that the same should apply to agonadal women. Men typically continue to take testosterone throughout life, but the risk of prostate disease should be discussed. Women given estrogens require screening mammography, and men taking testosterone require hematocrit, prostate exam and prostate-specific antigen testing according to national guidelines.

\section{Risks of Tumor Development}

Patients with DSDs have an increased risk of developing cancers of the germ cell lineage, malignant germ cell tumors or germ cell cancer (GCC) compared to the general population. Although precursor lesions are formed during embryonal or early post-partum development, the progression to invasive growth only occurs during or after puberty, often cited as a reason to delay surgery. A defined number of parameters are relevant in determining if and to what extent an individual patient is at risk. These include (1) genomic constitution, i.e., the presence of the Gonadoblastoma on the Y chromosome [GBY] region, and of the current best candidate gene TSPY; (2) the expression of the embryonic germ cell markers OCT3/4 (POU5F1) and/or KITL (stem cell factor) beyond the age of 1 year, and (3) the anatomical localization of the gonad(s). The histology of the precursor lesion depends on the level of gonadal testicularization, being carcinoma in situ (CIS)/intratubular germ cell neoplasia unclassified (IGCNU) of the (dysgenetic) testis (i.e., a higher risk level) and gonadoblastoma (GB) of the dysgenetic go$\operatorname{nad}(\mathrm{s})$ (i.e., a lower level). The earliest identifiable stage giving rise to $\mathrm{GB}$ is known as undifferentiated gonadal tissue. In general, the supportive cells of CIS/IGCNU are Sertoli cells (positive for SOX9), while those of GB are granulosa cells (positive for FOXL2), although costaining can be identified even within a single gonad. The di-

Global Disorders of Sex Development

Update since 2006 agnosis must be made by an experienced pathologist, supported by immunohistochemical staining data, and with full knowledge of the parameters and clinical data. Particularly, the possibility of delayed maturation must be considered in young children or the nonscrotal localization of a testis. Histological information is obtained from either a gonadal biopsy or gonadectomy. A welldesigned stratified approach can be followed to identify individuals who can undergo spontaneous puberty, possibly even life-long retention of no-risk or low-risk gonads.

It is well recognized that the highest risk prevalence $(30-50 \%)$ is seen in conditions characterized by disturbed gonadal development such as incomplete testis development combined with a full block of embryonic germ cell maturation in patients with $46, \mathrm{XY}$ gonadal dysgenesis and in some patients with $45, \mathrm{X} / 46, \mathrm{XY}$ DSDs. The degree of testicularization is reflected to some extent in the patient's phenotype with a low external masculinization score indicating a poorly differentiated gonad. Combined with knowledge on the underlying condition, GCC risk can be predicted. Conversely, individuals with testosterone biosynthesis disorders and androgen action disorders show a much lower risk $(<1-15 \%)$ for CIS development during childhood and a limited tendency towards invasive progression of the lesions, possibly inversely correlated to the degree of testosterone exposure/action. The clinical value of putative interesting diagnostic approaches, such as a more precise molecular diagnosis (next-generation sequencing) and noninvasive screening methods based on identified risk SNPs and novel serum (microRNA) markers, must be evaluated by skilled multidisciplinary DSD teams.

A recent publication proposes a model to assess the combined effect of epigenetic and environmental factors on the pathogenesis of GCC development [96]. Table 2 includes guidelines concerning the clinical management of GCC risk.

\section{Surgical Issues}

Since the Consensus Meeting in Chicago [1], DSD surgery continues to raise unresolved questions and dilemmas regarding indications, timing and procedures in the various categories of DSDs [97].

DSD surgery includes 4 main components [98]: (1) surgery of the genital tubercle which can be reduced in size (clitoroplasty) or reconstructed (hypospadias repair or phalloplasty; fig. 2-4); (2) the management of the Mül- 
Fig. 2. Anatomy of CAH genitalia showing the 3 main criteria to evaluate the degree of virilization: (1) the distance between the urethro-vaginal confluence and the perineal surface; (2) the length of the genital tubercle and the availability of urethral tissue to refashion the vaginal introitus, and (3) the fusion of the genital folds measured by the ratio ano-genital distance to ano-clitoral distance. $\mathrm{WG}=$ Week of gestation; $\mathrm{GT}=$ genital tubercle.

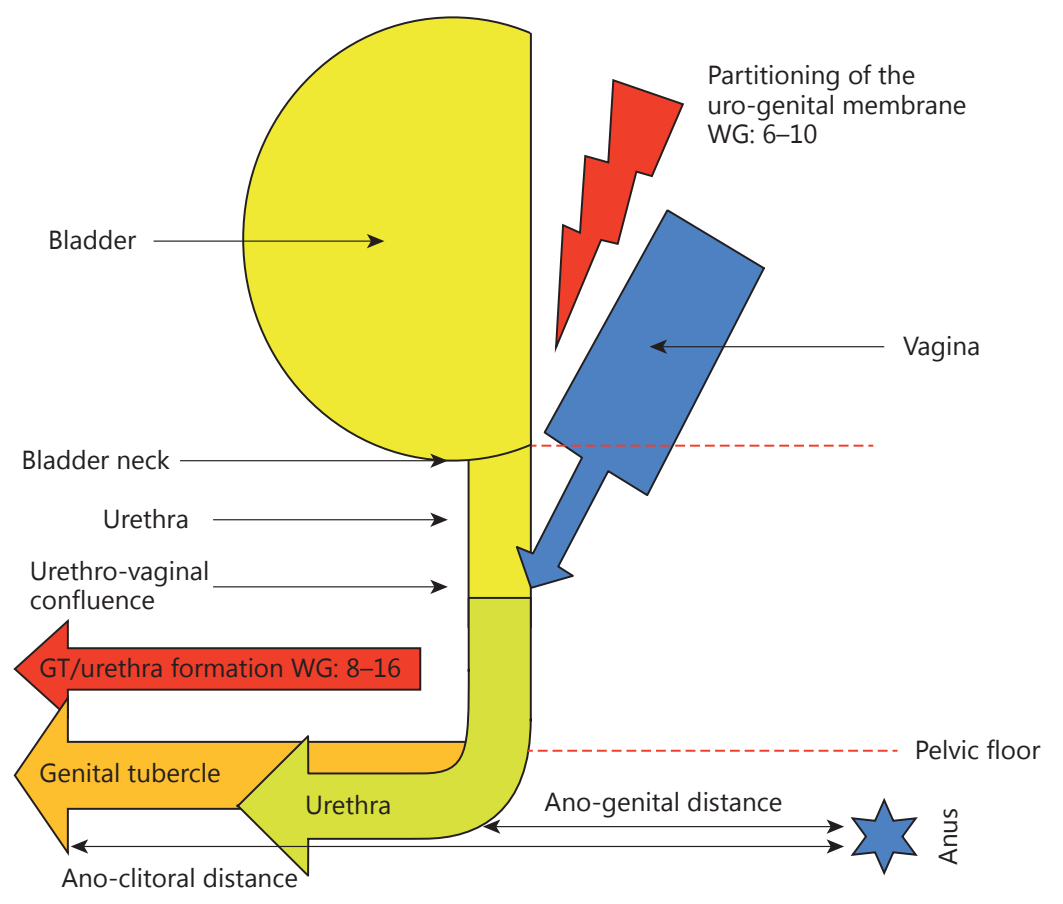

Table 2. GCC risk: clinical management

\begin{tabular}{|c|c|c|c|}
\hline & Male & Female & Unclear gender \\
\hline $\begin{array}{l}\text { Undervirilization } \\
\text { (46,XY: partial AIS, } \\
\text { complete AIS, } \\
\text { testosterone } \\
\text { synthesis disorders }\end{array}$ & $\begin{array}{l}\text { Post-pubertal biopsy } \\
\text { - Bilateral, CIS } \rightarrow \text { gonadectomy/irradiation } \\
\text { Repeat biopsy at } 10 \text { years of age } \\
\text { - Consider gonadectomy to avoid gynecomastia } \\
\quad \text { or if on testosterone supplementation }\end{array}$ & $\begin{array}{l}\text { Complete AIS - Postpubertal } \\
\text { gonadectomy or follow-up } \\
- \text { GCC risk low, allow } \\
\quad \text { spontaneous puberty }\end{array}$ & $\begin{array}{l}\text { - Low threshold for gonadectomy } \\
\text { Intensive psychological } \\
\text { counseling and follow-up }\end{array}$ \\
\hline
\end{tabular}

No data are available on the value of cryopreservation or safety if a precursor lesion for GCC is present.

lerian structures (vagina, uterus) which includes the connection of a vaginal cavity to the pelvic floor, vaginal substitution, dilatation of a vaginal cupule or removal of Müllerian remnants; (3) surgery of the gonads involves descent (orchiopexy), removal (tumor risk/late viriliza- tion) or biopsy for pathology or the preservation for reproduction, and (4) refashioning of the perineum (perineoplasty). Considerations for each of these procedures involve indications, timing, technical aspects, possible complications and long-term outcome. Such issues must 
Fig. 3. Anatomy of CAH genitalia after surgical repair showing the connection of the vagina to the perineum, the mucosal introitus, the reduced genital tubercle and the refashioned labia.

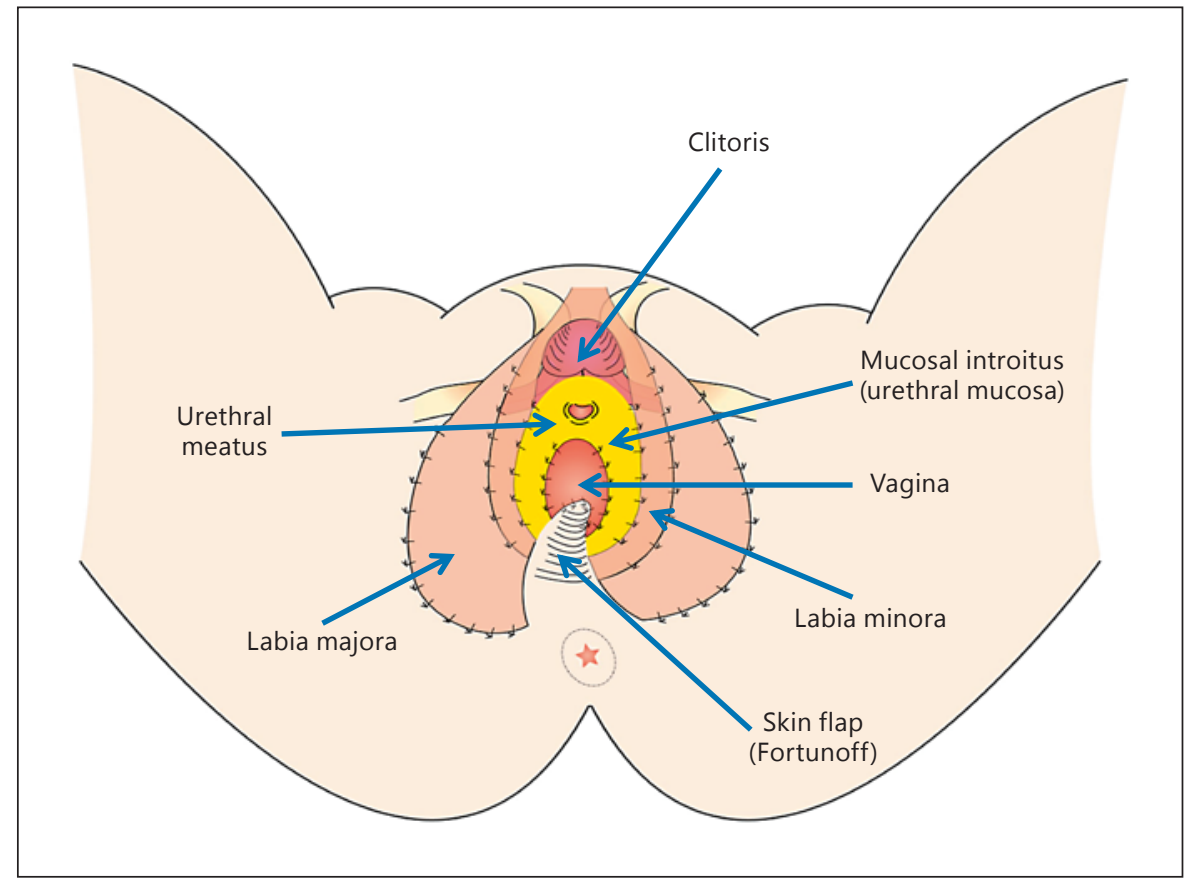

Fig. 4. Ventral aspect of a hypospadiac genital tubercle showing the ventral triangular defect formed by the proximal division of the corpus spongiosum. The tissues located in this triangle are hypoplastic and explain the ventral curvature of the genital tubercle.

Open

glans

Urethral

plate

Ectopic

meatus

Division of the corpus spongiosum 
be individually discussed with each patient/family for each DSD category.

A questionnaire considering the most sensitive situations in surgery has been circulated among a group of 32 experts (see consortium list in the Appendix), primarily surgeons, in order to establish some consensual guidelines for each specific situation. There is still no consensual attitude regarding indications, timing, procedure and evaluation of outcome of DSD surgery. The levels of evidence of responses given by the experts are low (B and C), while most are supported by team expertise. Literature reports are primarily short clinical series that cannot be compared because of heterogeneous pathologies and management. However, most experts agree with (1) the need for identifying centers of expertise with a multidisciplinary approach [19]; (2) a conservative management of the gonads in complete AIS patients [99, 100]; (3) avoidance of vaginal dilatation during childhood; (4) keeping asymptomatic Müllerian remnants during childhood which can be removed later if necessary [101]; (5) removal of biopsy-confirmed streak gonads [96], and (6) keeping $46, \mathrm{XY}$ cloacal exstrophy patients in the male gender [82, 102].

Timing, choice of the individual and irreversibility of surgical procedures are sources of concerns. There is no evidence regarding the impact of surgically treated or non-treated DSDs during childhood for the individual, the parents, society or the risk of stigmatization. The low level of evidence for management should lead multidisciplinary expert teams to design collaborative prospective studies involving all parties and using protocols of evaluation.

\section{Fertility}

The advancement of assisted fertility techniques has continued so that the potential for fertility is more likely albeit expensive. Fertility may be possible utilizing sperm retrieval and ICSI in patients who have functional gonads and do not require testosterone at puberty such as $\mathrm{XO} / \mathrm{XY}$ mosaicism, $5 a$-reductase deficiency and partial AIS patients. Further, if germ cells are present in the gonads such techniques may be possible among those requiring HRT. Among females, stimulation of ovulation and embryo transfer using fertilized donated ova have been used, including in females with $\mathrm{CAH}$ and Turner syndrome.

\section{Ethical, Legal and Cultural Issues}

No area of pediatric endocrinology engenders more controversy than the management of DSD conditions affecting reproductive development. With some variations, guidance from clinicians and ethicists has focused on principles and processes aimed at fostering the overall well-being of the child and future adult by: (1) minimizing physical and psychosocial risk; (2) preserving potential for fertility; (3) upholding the individual's rights to participate in decisions that will affect their now or later; (4) leaving options open for the future by avoiding irreversible treatments that are not medically necessary until the individual has the capacity to consent; (5) providing psychosocial support and PS; (6) supporting the individual's healthy sexual and gender identity development; (7) using a shared decision-making approach that respects the individual's and parents' wishes and beliefs; (8) respecting the family and parentchild relationships, and (9) providing patients with full medical information appropriate for age, developmental stage and cognitive abilities [103-105]. While each of these principles is important, striking the appropriate balance among them becomes challenging in the clinical setting. For example, respecting parents' wishes for early genital surgery may impinge on the child's right to participate in decision making and may reduce the child's options for the future.

In addition to guidance from within the medical community, there has been a recent marked increase in initiatives by governments and related agencies to develop ethical and legal frameworks for care [106-112]. Surgical intervention, in particular, has come under intense scrutiny, with a number of agencies condemning or calling for a complete moratorium on elective genital surgery or gonadectomy without the individual's informed consent $[108,111,112]$. Although parents are responsible for consenting to interventions believed on the basis of available evidence to be in the best interests of their child, their right to consent to non-medically necessary irreversible procedures that may adversely affect the child's future sexual function and/or reproductive capacity has been questioned, particularly when such parental decisions preclude the child's ability to be involved in decision making. In addition, many guidelines deem children's participation and input indispensable to decisions, especially those that will have a life-long deeply personal impact on their lives, with heightened awareness that young children, in particular, may not be able to vocalize adverse reactions to many interventions $[106,110,111]$. 
As a consequence of the efforts of some patient advocacy groups in partnership with allies within and beyond the medical community, legal challenges have been brought against practices that were considered standard of care in the management of children with atypical genital or reproductive anatomy in the 1970s to 1990s. This has resulted in litigation or ruling against the practice of genital surgery or gonadectomy without patient consent as a breach of fundamental reproductive rights and bodily autonomy in some circumstances [e.g., Columbia, Australia, Kenya, South Carolina (USA)]. In addition, provision has been made in some jurisdictions (e.g., Australia, Germany, Malta) for the registration of the sex of a child to be postponed or lodged as 'other' in situations in which it is unclear.

Although fundamental human rights are generally considered universal, irrespective of race, gender, nationality, religion or other factors, the interpretation of those rights is shaped by the cultural and socioeconomic context, contributing to even greater complexity in ethical and legal frameworks regarding care. An evaluation of the application of ethical principles developed in Western settings would be useful in other cultural settings.

The disciplines of ethics and law are dynamic, and a continuing evolution is to be expected as individuals within and across fields address a genuine struggle regarding appropriate care for children and families living with these conditions. Physicians working with these families should be aware that the trend in recent years has been for legal and human rights bodies to increasingly emphasize preserving patient autonomy.

\section{Appendix}

In addition to the primary authors, the following members of the Global DSD Update Group contributed to the writing of this document:

\section{Members of the Global DSD Update Consortium}

François Ansermet*, Psychiatrist, Geneva, Switzerland; Linda Baker*, Pediatric Urologist, Dallas, Tex., USA; Alicia V. Belgorovsky, Endocrine Service, Hospital de Pediatria Garrhan, Buenos Aires, Argentina; Larry Baskin*, Pediatric Urologist, San Francisco, Calif., USA; Sheri A. Berenbaum, Psychology and Pediatrics, The Pennsylvania State University, University Park, Pa., USA; Claire Bouvattier, Service d'Endocrinologie et Diabète de l'Enfant, Hôpital du Kremlin-Bicêtre, Paris, France; Luis Braga*, Pediatric Urologist, Toronto, Ont., Canada; Anthony Caldamone*, Pediatric Urologist, Editor in Chief of the Journal of Pediatric Urology, Providence, R.I., USA; Nina Callens, University of Michigan, Ann Arbor, Mich., USA; Evangelia Charmandari, Division of Endocrinology, Metabolism and Diabetes, First Department of Pediatrics, University of Athens Medical School 'Aghia
Sophia' Children's Hospital, Athens, Greece; John M. Chigiti, Kenya School of Law, Nairobi, Kenya; Peggy T. Cohen-Kettenis, Medical Psychology, VU University Medical Center, Amsterdam, The Netherlands; Felix Conte, University of California San Francisco Medical School, San Francisco, Calif., USA; Martine Cools, University of Gent, Ghent, Belgium; Gerard S. Conway, University College London, London, UK; Georgiann Davis, University of Nevada, Las Vegas, Nev., USA, President of AIS-DSD Support Group US; Natalie Delimata, Institute of Technology, Sligo, Ireland; Stenvert L.S. Drop, Sophia Children's Hospital/Erasmus MC, Rotterdam, The Netherlands; Lise Duranteau*, Adolescent Obstetrician and Gynecologist, Paris, France; Annastasia Ediati, Faculty of Psychology, Diponegoro University, Semarang, Indonesia; Christa Flück, Division of Pediatric Endocrinology and Diabetology, Inselspital, University of Bern, Bern, Switzerland; Jameson Garland, Law Department, Uppsala University, Uppsala, Sweden; Claire-Lise Gay*, Pediatric Endocrinologist, Lyon, France; Alaa El Ghoneimi*, Pediatric Urologist, Paris, France; Lynn Gillam, Children's Bioethics Centre, Royal Children's Hospital, Melbourne School of Population and Global Health, University of Melbourne, Melbourne, Vic., Australia; Daniela Gorduza*, Pediatric Surgeon, Lyon, France; Massimo Di Grazia*, Psychologist, Cosenga, Italy; Janet Green, Accord Alliance, Whitehouse Station, N.J., USA; Gil Guerra-Junior, Department of Pediatrics, School of Medical Sciences, State University of Campinas, Campinas, Brazil; Terry Hensle*, Pediatric Urologist, New York, N.Y., USA; Melissa Hines, Department of Psychology, University of Cambridge, Cambridge, UK; Piet Hoebeke*, Pediatric and Adolescent Urologist, Ghent, Belgium; Reiko Horikawa, Division of Endocrinology and Metabolism, Center for Child Health and Development, Tokyo, Japan; Martin Kaefer*, Pediatric Urologist, Indianapolis, Ind., USA; Julius Kaganzi Kaggwa, Support Initiative for People with Congenital Disorders, Kampala, Uganda; Katrina Karkazis, Center for Biomedical Ethics, Stanford University, Stanford, Calif., USA; Tom Kolon*, Pediatric Urologist, Philadelphia, Pa., USA; Nicolas Kalfa*, Pediatric Surgeon, Montpellier, France; Mary M. Lee, UMass Memorial Children's Medical Center, Worcester, Mass., USA; Arianna Lesma*, Pediatric Urologist, Milan, Italy; Kah Yin Loke, Department of Paediatrics, KTP-University Children's Medical Institute, National University of Singapore, Singapore; Gianantonio Manzoni*, Pediatric Urologist, Milan, Italy; Giacinto Marrocco*, Pediatric Urologist, Rome, Italy; Emilio Merlini*, Pediatric Urologist, Turin, Italy; Jim Moore, Association for X and Y Chromosome Variations, Pine, Colo., USA; Miriam B. Muscarella, Accord Alliance and dsdfamilies.org, Cambridge, Mass., USA; Agneta Nordenskjöld*, Pediatric Urologist, Stockholm, Sweden; Joao L. Pippi Salle, Pediatric Urologist, Sidra, Qatar; Dix Phillip Poppas*, Pediatric Urology, Weill Cornell Medical Center, New York, N.Y., USA; Philip Ransley*, Pediatric Urologist, London, UK; Katrina Roen, University of Oslo, Oslo, Norway; Marco Rivarola, Endocrine Service, Hospital de Pediatria Garrhan, Buenos Aires, Argentina; Rodolfo Rey, Centro de Investigaciones Endocrinológicas 'Dr. César Bergadá' (CEDIE), CONICET, FEI, División de Endocrinología, Hospital de Niños R. Gutiérrez, Buenos Aires, Argentina; Waifro Rigamonti*, Pediatric Urologist, Trieste, Italy; Richard Rink*, Pediatric Urologist, Indianapolis, Ind., USA; Rodrigo Romao*, Pediatric Urologist, Halifax, N.S., Canada; Wilma Rossi, Children's Hospital of Philadelphia, Pearlman School of Medicine, University of Pennsylvania, Philadelphia, Pa., USA; Léon Sann*, Neonatologist, 
Ethicist, Lyon, France; Justine M. Schober*, Department of Pediatric Urology, University of Pittsburgh Medical Center Hamot, Erie, Pa., USA; Hisham Sibai*, Pediatric Urologist, Casablanca, Morocco; Margaret Simmonds, Androgen Insensitivity Support Group (AISSG), London, UK; Arlene Smith, Turner Syndrome Support Society, Clydebank, UK; Shubha Srinivasan, Children's Hospital at Westmead, Sydney, N.S.W., Australia; Maayan Sudai, Harvard Law School, Boston, Mass., USA; Sajid Sultan*, Pediatric Urologist, Karachi, Pakistan; Maria Vogiatzi, Division of Endocrinology and Diabetes, Children's Hospital of Philadelphia, Phil- adelphia, Pa., USA; Jan Walker, Sydney Children's Hospital, Randwick, N.S.W., Australia; Gary Warne, Department of Paediatrics, University of Melbourne, Melbourne, Vic., Australia; Claudia Wiesemann, Institut für Ethik und Geschichte der Medizin, Universitätsmedizin Göttingen, Göttingen, Germany; Amy Wisniewski*, The University of Oklahoma Health Sciences Center, Oklahoma City, Okla., USA; Kimberly Zieselman, Advocates for Informed Choice, Cotati, Calif., USA.

* Designates those who participated in the survey in the Surgical Issues section.

\section{References}

$\checkmark 1$ Lee PA, Houk CP, Ahmed SF, Hughes IA: Consensus Statement on Management of Intersex Disorders. International Consensus Conference on Intersex. Pediatrics 2006; 118:E488-E500.

2 Pasterski V, Prentice P, Hughes IA: Consequences of the Chicago consensus on disorders of sex development (DSD): current practices in Europe. Arch Dis Child 2010;95:618623.

3 Lin-Su K, Lekarev O, Poppas DP, Vogiatzi MG: Congenital adrenal hyperplasia patient perception of 'disorders of sex development' nomenclature. Int J Pediatr Endocrinol 2015; 2015(1)9.

4 Blackless M, Charuvastra A, Derryck A, Fausto-Sterling A, Lauzanne K, Lee E: How sexually dimorphic are we? Review and synthesis. Am J Hum Biol 2000;12:151-166.

5 Sax L: How common is intersex? A response to Anne Fausto-Sterling. J Sex Res 2002;39: 174-178.

6 6 Nistal M, Paniagua R, Gonzalez-Peramato P, Reyes-Mugica M: Ovotesticular DSD (true hermaphroditism). Pediatr Dev Pathol 2015; 18:345-352.

7 Skakkebaek NE, Rajpert-De Meyts E, Main $\mathrm{KM}$ : Testicular dysgenesis syndrome: an increasingly common developmental disorder with environmental aspects. Hum Reprod 2001;16:972-978.

8 Pang SY, Wallace MA, Hofman L, Thuline HC, Dorche C, Lyon IC, Dobbins RH, Kling S, Fujieda K, Suwa S: Worldwide experience in newborn screening for classical congenital adrenal hyperplasia due to 21-hydroxylase deficiency. Pediatrics 1988;81:866-874.

-9 Thyen U, Lanz K, Holterhus PM, Hiort O: Epidemiology and initial management of ambiguous genitalia at birth in Germany. Horm Res 2006;66:195-203.

$\longrightarrow 10$ Nordenvall AS, Frisen L, Nordenstrom A, Lichtenstein, Norenskjold A: Population based nationwide study of hypospadias in Sweden, 1973 to 2009: incidence and risk factors. J Urol 2014;191:783-789.

11 World Health Organization: Mental Health Action Plan 2013-2020. http://www.who.int/ mental_health/publications/action_plan/en (accessed 1/1/2016).
12 AIS-DSD Support Group Research Policy. http://aisdsd.org/ais-dsd-support-group-official-research-policy/ (accessed April 26, 2015).

13 The World Professional Association for Transgender Health, Standards of Care for the Health of Transsexual, Transgender, and Gender Nonconforming People. 7th version, 2011. http://www.wpath.org (accessed April 26, 2015).

14 United Nations Office of Human Rights High Commissioner: UN Intersex Fact Sheet. https://www.unfe.org/system/unfe-65-Intersex_Factsheet_ENGLISH.pdf) (accessed November 27, 2015).

15 Creighton S, Minto CL, Liao L-M, Alderson J, Simmonds M: Meeting between experts: evaluation of the first UK Forum for lay and professional experts in intersex. Patient Educ Couns 2004;54:153-157.

16 Baratz AB, Sharp MK, Sandberg DE: Disorders of sex development peer support; in Hiort O, Ahmed S (eds): Understanding Differences and Disorders of Sex Development (DSD). Basel, Karger, 2014, pp 99-112.

17 Osuch JR, Silk K, Price C, Barlow J, Miller K, Hernick A, Fonfa A: A historical perspective on breast cancer activism in the United States: from education and support to partnership in scientific research. J Womens Health (Larchmt) 2012;21:355-362.

18 Davis G, Feder EK: Narrative symposium: intersex. Narrat Inq Bioeth 2015;5:87-150.

19 Ahmed SF, Achermann JC, Arlt W, Balen AH, Conway G, Edwards ZL, Elford S, Hughes IA, Izatt L, Krone N, Miles HL, O’Toole S, Perry L, Sanders C, Simmonds M, Wallace AM, Watt A, Willis D: UK guidance on the initial evaluation of an infant or an adolescent with a suspected disorder of sex development. Clin Endocrinol (Oxf) 2011;75:12-26.

20 Wilson JD, Rivarola MA, Mendonca BB, Warne GL, Josso N, Drop SL, Grumbach MM: Advice on the management of ambiguous genitalia to a young endocrinologist from experienced clinicians. Semin Reprod Med 2012;30:339-350.

21 Adam MP, Fechner PY, Ramsdell LA, Badaru A, Grady RE, Pagon RA, McCauley E, Cheng EY, Parisi MA, Shnorhavorian M: Ambigu- ous genitalia: what genetic testing is practical? Am J Med Genet A 2012;158A:13371343.

22 Flück CE, Pandey AV, Huang N, Agrawal V, Miller WL: P450 oxidoreductase deficiency a new form of congenital adrenal hyperplasia. Endocr Dev 2008;13:67-81.

23 Grinspon RP, Loreti N, Braslavsky D, Valeri C, Schteingart H, Ballerini MG, Bedecarrás P, Ambao V, Gottlieb S, Ropelato MG, Bergadá I, Campo SM, Rey RA: Spreading the clinical window for diagnosing fetal-onset hypogonadism in boys. Front Endocrinol (Lausanne) 2014;5:51.

24 Dean A, Sharpe RM: Clinical review: Anogenital distance or digit length ratio as measures of fetal androgen exposure: relationship to male reproductive development and its disorders. J Clin Endocrinol Metab 2013;98:22302238.

25 Jayachandran D, Bythell M, Platt MW, Rankin J: Register based study of bladder exstrophy-epispadias complex: prevalence, associated anomalies, prenatal diagnosis and survival. J Urol 2011;186:2056-2060.

26 Hutson JM, Grover SR, O’Connell M, Pennell SD: Malformation syndromes associated with disorders of sex development. Nat Rev Endocrinol 2014;10:476-487.

27 Farrugia MK, Sebire NJ, Achermann JC, Eisawi A, Duffy PG, Mushtaq I: Clinical and gonadal features and early surgical management of $45, \mathrm{X} / 46, \mathrm{XY}$ and $45, \mathrm{X} / 47, \mathrm{XYY}$ chromosomal mosaicism presenting with genital anomalies. J Pediatr Urol 2013;9:139-144.

28 Groth KA, Skakkebæk A, Høst C, Gravholt $\mathrm{CH}$, Bojesen A: Clinical review: Klinefelter syndrome - a clinical update. J Clin Endocrinol Metab 2013;98:20-30.

29 Tomlinson C, Macintyre H, Dorrian CA, Ahmed SF, Wallace AM: Testosterone measurements in early infancy. Arch Dis Child Fetal Neonatal Ed 2004;89:F558-F559.

30 Bergadá I, Milani C, Bedecarrás P, Andreone L, Ropelato MG, Gottlieb S, Bergadá C, Campo S, Rey RA: Time course of the serum gonadotropin surge, inhibins, and anti-Müllerian hormone in normal newborn males during the first month of life. J Clin Endocrinol Metab 2006;91:4092-4098. 
-31 Kuiri-Hanninen T, Seuri R, Tyrvainen E, Turpeinen U, Hamalainen E, Stenman UH, Dunkel L, Sankilampi U: Increased activity of the hypothalamic-pituitary-testicular axis in infancy results in increased androgen action in premature boys. J Clin Endocrinol Metab 2011;96:98-105.

-32 Kulle AE, Riepe FG, Melchior D, Hiort O, Holterhus PM: A novel ultrapressure liquid chromatography tandem mass spectrometry method for the simultaneous determination of androstenedione, testosterone, and dihydrotestosterone in pediatric blood samples: age- and sex-specific reference data. J Clin Endocrinol Metab 2010;95:2399-2409.

- 33 Krone N, Hughes BA, Lavery GG, Stewart PM, Arlt W, Shackleton CHL: Gas chromatography/mass spectrometry (GC/MS) remains a pre-eminent discovery tool in clinical steroid investigations even in the era of fast liquid chromatography tandem mass spectrometry (LC/MS/MS). J Steroid Biochem Mol Biol 2010;121:496-504.

- 34 Josso N, Rey R, Picard JY: Testicular antiMüllerian hormone: clinical applications in DSD. Semin Reprod Med 2012;30:364-373.

- 35 Rey RA, Grinspon RP: Normal male sexual differentiation and aetiology of disorders of sex development. Best Pract Res Clin Endocrinol Metab 2011;25:221-238.

-36 Grinspon RP, Rey RA: When hormone defects cannot explain it: malformative disorders of sex development. Birth Defects Res C Embryo Today 2014;102:359-373.

-37 Bouvattier C, Carel JC, Lecointre C, David A, Sultan C, Bertrand AM, Morel Y, Chaussain JL: Postnatal changes of T, LH, and FSH in 46,XY infants with mutations in the AR gene. J Clin Endocrinol Metab 2002;87:29-32.

- 38 Lindhardt Johansen M, Hagen CP, Johannsen TH, Main KM, Picard JY, Jorgensen A, Rajpert-De Meyts E, Juul A: Anti-müllerian hormone and its clinical use in pediatrics with special emphasis on disorders of sex development. Int J Endocrinol 2013;2013:198698.

-39 Flück CE, Pandey AV: Steroidogenesis of the testis - new genes and pathways. Ann Endocrinol (Paris) 2014;75:40-47.

-40 Auchus RJ, Miller WL: Defects in androgen biosynthesis causing 46,XY disorders of sexual development. Semin Reprod Med 2012;30: 417-426.

41 Arlt W, Biehl M, Taylor AE, Hahner S, Libe R, Hughes BA, Schneider P, Smith DJ, Stiekema H, Krone N, Porfiri E, Opocher G, Bertherat J, Mantero F, Allolio B, Terzolo M, Nightingale $\mathrm{P}$, Shackleton $\mathrm{CH}$, Bertagna X, Fassnacht M, Stewart PM: Urine steroid metabolomics as a biomarker tool for detecting malignancy in adrenal tumors. J Clin Endocrinol Metab 2011;96:3775-3784.

42 Arboleda VA, Sandberg DA, Vilain E: DSDs: genetics, underlying pathologies and psychosexual differentiation. Nat Rev Endocrinol 2014; 10:603-615.

-43 Stout SA, Litvak M, Robbins NM, Sandberg DE: Congenital adrenal hyperplasia: classifi- cation of studies employing psychological endpoints. Int J Pediatr Endocrinol. 2010; 2010:191520.

44 Roen K: 'But we have to do something': surgical 'correction' of atypical genitalia. Body Soc 2008; 14:47-66.

45 Liao L-M: Towards a clinical-psychological approach to address the heterosexual concerns of intersexed women; in Clarke V, Peel E (eds): Out In Psychology: Lesbian, Gay, Bisexual and Transgender Perspectives. Chichester, Wiley, 2007, pp 391-408.

46 Machado PS, Costa AB, Nardi HC, Fontanari AMV, Araujo IR, Knauth DR: Follow-up of psychological outcomes of interventions in patients with disorders of sexual development: a systemic review. J Health Psychol 2015, Epub ahead of print.

-47 Nordensköld A, Holmdahl G, Frisen L, Falhammar H, Filipsson H, Thoren M, Hagenfeldt K: Type of mutation and surgical procedure affect long-term quality of life for women with congenital adrenal hyperplasia. J Clin Endocrinol Metab 2008;93;380-386.

48 Schweizer K, Brunner F, Handford C, RichterAppelt $\mathrm{H}$ : Gender experience and satisfaction with gender allocation in adults with diverse intersex conditions (divergences of sex development, DSD). Psychol Sex 2014;5:56-82.

49 Davis G: The power in a name: diagnostic terminology and diverse experiences. Psychol Sex 2014;5:15-27.

50 Alderson J, Madill A, Balen A: Fear of devaluation: understanding the experience of intersexed women with androgen insensitivity syndrome. Br J Health Psychol 2004;9:81100.

51 Schönbucher V, Schweizer K, Richter-Appelt $\mathrm{H}$ : Sexual quality of life of individuals with disorders of sex development and a 46,XY karyotype: a review of international research. J Sex Marital Ther 2010;36:193-215.

52 Chadwick PM, Liao LM, Boyle M: Size Matters: Experiences of atypical genital and sexual development in males. J Health Psychol 2005; 10:529-543

53 Boyle M, Smith S, Liao L-M: Adult genital surgery for intersex women: a solution to what problem? J Health Psychol 2005;10:573584 .

54 Minto CL, Liao LM, Woodhouse CRJ, Ransley PJ, Creighton SM: Adult outcomes of childhood clitoral surgery for ambiguous genitalia. Lancet 2003;361:1252-1257.

55 Crouch NS, Liao LM, Woodhouse CRJ, Conway GS, Creighton SM: Genital sensitivity and sexual function following childhood cosmetic genital surgery: results based on women with congenital adrenal hyperplasia. J Urol 2008;179:634-638.

-56 Minto CL, Liao KLM, Conway GS, Creighton SM: Sexual function in women with complete androgen insensitivity syndrome. Fertil Steril 2003;80:157-164.

57 Kohler B, Kleinemeier E, Lux A, Hiort O, Gruters A, Thyen U; DSD Network Working Group: Satisfaction with genital surgery and sexual life of adults with XY disorders of sex development: results from the German clinical evaluation study. J Clin Endocrinol Metab 2012;97:577-588.

58 Warne G, Grover S, Hutson JM, Sinclair A, Metcalfe S, Northam E, Freeman J; Murdoch Childrens Research Institute Sex Study Group: A long-term outcome study of intersex conditions. J Pediatr Endocrinol Metab 2005;18:555-567.

59 Lean WL, Deshpande A, Hutson J, Grover SR: Cosmetic and anatomic outcomes after feminizing surgery for ambiguous genitalia. J Pediatr Surg 2005;40:1856-1860

60 Crissman H, Warner L, Gardner M, et al: Children with disorders of sex development: a qualitative study of early parental experience. Int J Pediatr Endocrinol 2011;2011:10.

61 Liao L-M, Green H, Creighton SM, Crouch NS, Conway GS: 'Service users' experiences of obtaining and giving information about disorders of sex development. Br J Obstet Gynaecol 2010;117:193-199.

62 Weijenborg PT, ter Kuile MM: The effect of a group programme on women with the Meyer Rokitansky Küster Hauser syndrome. Br J Obstet Gynaecol 2000;107:365-368.

63 Heller-Boersma JG, Schmidt UH, Edmonds DK: A randomized controlled trial of a cognitive-behavioural group intervention versus waiting-list control for women with uterovaginal agenesis (Mayer-Rokitansky-KüsterHauser Syndrome: MRKH). Hum Reprod 2007;22:2296-2301.

64 Chadwick PM, Smyth A, Liao LM: A group intervention to improve self-esteem for women diagnosed with Turner's syndrome. J Pediatr Adolesc Gynecol 2014;27:129-132.

65 Roen K, Pasterski V: Psychological research and intersex/DSD: recent developments and future directions. Psychol Sex 2014;5:102116.

66 Duguid A, Morrison S, Robertson A, Chalmers J, Youngson G, Ahmed SF: The psychological impact of genital anomalies on the parents of affected children. Acta Paediatr 2007; 96:348-352.

67 American Psychiatric Association: Diagnostic and Statistical Manual of Mental Disorders, ed 5. DSM-5. Arlington, American Psychiatric Association, 2013.

68 Schweizer K, Brunner F, Schützmann K, Schönbucher V, Richter-Appelt H: Gender identity and coping in female $46, \mathrm{XY}$ adults with androgen biosynthesis deficiency (intersexuality/DSD). J Couns Psychol 2009;56: 189-201.

69 Meyer-Bahlburg HFL: Gender monitoring and gender reassignment of children and adolescents with a somatic disorder of sex development. Child Adolesc Psychiatr Clin N Am 2011;20:639-649.

70 Rösler A, Kohn G: Male pseudohermaphroditism due to $17 \beta$-hydroxysteroid dehydrogenase deficiency: studies on the natural history of the defect and effect of androgens on gender role. J Steroid Biochem 1983;19:663-674. 
71 Smith ES, Junger J, Derntl B, Habel U: The transsexual brain - a review of findings on the neural basis of transsexualism. Neurosci Biobehav Rev 2015;59:251-266.

72 Swaab DF, Gooren LJG, Hofman MA: The human hypothalamus in relation to gender and sexual orientation. Prog Brain Res 1992; 93:205-219.

73 Berenbaum SA, Beltz AM: Sexual differentiation of human behavior: effects of prenatal and pubertal organizational hormones. Front Neuroendocrinol 2011;32:183-200.

74 Hines M: Gender development and the human brain. Annu Rev Neurosci 2011;34:67-86.

75 Hines M, Constantinescu M, Spencer D: Early androgen exposure and human gender development. Biol Sex Differ 2015;6:3.

76 Cadet P: Androgen insensitivity syndrome with male sex-of-living. Arch Sex Behav 2011; 40:1101-1102.

-77 Pasterski V, Acerini CL, Dunger DB, Ong KK, Hughes IA, Thankamony A, Hines M: Postnatal penile growth concurrent with mini-puberty predicts later sex-typed play behavior: evidence for neurobehavioral effects of the postnatal androgen surge in typically developing boys. Horm Behav 2015;69:98-105.

78 Meyer-Bahlburg HFL, Baratz Dalke K, Berenbaum SA, Cohen-Kettenis PT, Hines M, Schober JM: Gender assignment, reassignment, and outcome in disorders of sex development: update of the 2005 Consensus Conference. Horm Res Paediatr DOI: 10.1159/000442386.

-79 Nordenström A, Frisén L, Falhammar H, Filipsson H, Holmdahl G, Janson PO, Thorén M, Hagenfeldt K, Nordenskjöld A: Sexual function and surgical outcome in women with congenital adrenal hyperplasia due to CYP21A2 deficiency: clinical perspective and the patients' perception. J Clin Endocrinol Metab 2010;95:3633-3640.

- 80 Frisén L1, Nordenström A, Falhammar H, Filipsson H, Holmdahl G, Janson PO, Thorén M, Hagenfeldt K, Möller A, Nordenskjöld A: Gender role behavior, sexuality, and psychosocial adaptation in women with congenital adrenal hyperplasia due to CYP21A2 deficiency. J Clin Endocrinol Metab 2009;94 3432-3439.

-81 Lee PA, Houk CP, Husmann DA: Should male gender assignment be considered in the markedly virilized patient with 46,XX and congenital adrenal hyperplasia? J Urol 2010 184:1786-1792.

82 Diamond DA, Burns JP, Huang L, Rosoklija I, Retik AB: Gender assignment for newborns with 46XY cloacal exstrophy: a 6-year followup survey of pediatric urologists. J Urol 2011; 186(suppl 4):1642-1648

83 Kolesinska Z, Ahmed SF, Niedziela M, et al Changes over time in sex assignment for disorders of sex development. Pediatrics 2014; 134:e710--e715.

84 Cohen-Kettenis PT: Gender change in 46,XY persons with 5-alpha-reductase-2 deficiency and 17-beta-hydroxysteroid dehydroge- nase-3 deficiency. Arch Sex Behav 2005;34: 399-410.

85 Barseghyan H, Vilain E: The genetics of ovotesticular disorders of sex development; in New MI, Lekarev O, Parsa A, Yuen TT, O’Malley B, Hammer GD (eds): Genetic Steroid Disorders. London, Waltham/San Diego, Academic Press/Elsevier, 2014, pp 261-263.

86 Damiani D, Guedes DR, Damiani D, Setian N, Maciel-Guerra AT, Mello MP, Guerra-Júnior G: True Hermaphroditism: experience with 36 patients. Arq Bras Endocrinol Metabol 2005;49:71-78.

-87 Jaruratanasirikul S, Engchaun V: Management of children with disorders of sex development: 20-year experience in southern Thailand. World J Pediatr 2014;10:168-174.

88 Sircili MHP, Denes FT, Costa EMF, Machado MG, Inacio M, Silva RB, Srougi M, Mendonca BB, Domenice S: Long-term follow-up of a large cohort of patients with ovotesticular disorder of sex development. J Urol 2014;191: 1532-1536.

89 Weston WW: Informed and shared decisionmaking: The crux of patient-centred care. CMAJ 2001; 165:438-439.

-90 Muscarella M, Kranenburg-van Koppen L, Grijpink-van den Biggelar K, Drop SLS: Global application of DSD-related electronic (e) resources: e-learning, e-consultation and einformation sharing; in Hiort O, Ahmed SF (eds): Understanding Differences and Disorders of Sex Development (DSD). Endocr Dev. Basel, Karger, 2014, pp 268-283.

91 Siminoff LA, Sandberg DE: Promoting shared decision making in disorders of sex development (DSD): decision aids and support tools. Horm Metab Res 2015;47:335-339.

92 IOM (Institute of Medicine): Establishing transdisciplinary professionalism for improving health outcomes: workshop summary. Washington, The National Academies Press, 2014.

93 Sandberg DE, Gardner M, Cohen-Kettenis PT: Psychological aspects of the treatment of patients with disorders of sex development. Semin Reprod Med 2012;30:443-452.

94 American Academy of Pediatrics; American Academy of Family Physicians; American College of Physicians-American Society of Internal Medicine: A consensus statement on health care transitions for young adults with special health care needs. Pediatrics 2002;110: 1304-1306.

95 Crouch NS, Creighton SM: Transition of care for adolescents with disorders of sex development. Nat Rev Endocrinol 2014;10:436-442.

96 Van der Zwan YG, Biermann K, Wolffenbuttel KP, Cools M, Looijenga LHJ: Gonadal maldevelopment as risk factor for germ cell cancer: towards a clinical decision model. Eur Urol 2015;67:692-701.

97 Mouriquand P, Caldamone A, Malone P, Frank JD, Hoebeke P: The ESPU/SPU standpoint on the surgical management of Disorders of sex development (DSD). J Pediatr Urol 2014;10:8-10.
98 Vidal I, Gorduza DB, Haraux E, Gay CL, Chatelain P, Nicolino M, Mure PY, Mouriquand P: Surgical options in DSD with ambigous genitalia. Best Pract Res Clin Endocrinol Metab 2010;24:311-324.

99 Bouvattier C: Androgen receptor defects: syndromes of androgen insensitivity. Disorders of sex development: endocrine aspects; in Gearhart J, Rink R, Mouriquand P (eds): Pediatric Urology, ed 2. Philadelphia, Saunders Elsevier, 2010, p 472e3.

100 Nakhal RS, Hall-Craggs M, Freeman A, Kirkham A, Conway GS, Arora R, Woodhouse CR, Wood DN, Creighton SM: Evaluation of retained testes in adolescent girls and women with complete androgen insensitivity syndrome. Radiology 2013;268:153-160.

101 Josso N, Belville C, Di Clemente N, Picard JY: $\mathrm{AMH}$ and $\mathrm{AMH}$ receptor defects in persistent Müllerian duct syndrome. Hum Reprod Update 2005;11:351-356.

102 Meyer-Bahlburg HFL: Gender identity outcome in female-raised 46,XY persons with penile agenesis, cloacal exstrophy of the bladder, or penile ablation. Arch Sex Behav 2005;34:423-438

103 Gillam LH, Hewitt JK, Warne GL: Ethical principles for the management of children with disorders of sex development. Horm Res Pediatr 2010;74:412-418.

104 Karkazis K, Rossi W: Ethics for the pediatrician: disorders of sex development: optimizing care. Pediatr Rev 2010;31:e82-e85.

105 Wiesemann C, Ude-Koeller S, Sinnecker GH, Thyen U: Ethical Principles and Recommendations for the medical management of differences of sex development (DSD)/intersex in children and adolescents. Eur J Pediatr 2010:169:671-679.

106 Council of Europe Commissioner for $\mathrm{Hu}$ man Rights. Human Rights and Intersex People. April 2015.

107 Council of Europe, Parliamentary Assembly (PACE). Resolution 1952 (2013), final version on children's rights to physical integrity. October 1, 2013, para 7.5.3.

108 European Union Agency for Fundamental Rights. The Fundamental Rights Situation of Intersex People. FRA Focus. April 2015.

109 German Ethics Council 2013. Intersexuality (Opinion). http://www.ethikrat.org/files/ opinion-intersexuality.pdf (accessed $1 / 1 / 2016)$.

110 Swiss National Advisory Committee on Biomedical Ethics: On the Management of Differences of Sex Development: Ethical Issues Relating to Intersexuality. Opinion number 20/2012. Bern, November 2012.

111 United Nations Convention on the Rights of the Child. Committee on the Rights of the Child (CRC/C/CHE/CO/2-4). February 4, 2015.

112 United Nations General Assembly, Human Rights Council. Discrimination and Violence against Individuals Based on their Sexual Orientation and Gender Identity. A/ HRC/29/23. May 2015. 


\section{Errata}

The Australasian Pediatric Endocrine Group (APEG) contributed substantially to the composition of the recent publication 'Global disorders of sex development update since 2006: perceptions, approach and care' by Lee et al. [Horm Res Paediatr 2016;85:158-180, DOI: $10.1159 / 000442975$ ], but did not endorse this document. Dr. Peter Koopman provided considerable input and should have been listed among the members of the Global DSD Update Consortium.

In the appendix of the recent publication by Lee et al. entitled 'Global disorders of sex development update since 2006: perceptions, approach and care' [Horm Res Paediatr 2016;85:158-180, DOI: 10.1159/000442975], Massimo Di Grazia, Psychologist, is incorrectly mentioned to be from Cosenga, Italy. The correct city is Trieste, Italy. 